\title{
Submesoscale Dynamics in the Northern Gulf of Mexico. Part I: Regional and Seasonal Characterization and the Role of River Outflow 0
}

\author{
Roy Barkan, James C. McWilliams, Alexander F. ShChepetkin, M. Jeroen Molemaker, \\ AND LIONEL RENAULT \\ Department of Atmospheric and Oceanic Sciences, University of California, Los Angeles, Los Angeles, California
}

\author{
ANNALISA BRACCO AND JUN CHOI \\ School of Earth and Atmospheric Sciences, Georgia Institute of Technology, Atlanta, Georgia
}

(Manuscript received 22 February 2017, in final form 11 July 2017)

\begin{abstract}
Realistic, submesoscale-resolving numerical simulations are used to characterize the flow's statistics and the geography of surface submesoscale currents in the northern Gulf of Mexico. This study examines the role of the Mississippi-Atchafalaya River system in driving submesoscale currents during winter and summer, on and off the shelf, by investigating two sets of statistically equilibrated solutions, with and without river forcing. In this paper, the first of three, the authors analyze vorticity $\zeta$, horizontal divergence $\delta$, and available potential energy to eddy kinetic energy conversion $\overline{w^{\prime} b^{\prime}}$ and show that river forcing has an important effect on the spatial distribution and magnitudes of submesoscale currents in both seasons. During winter, solutions without river forcing display an increase in seasonal-mean values of $\zeta, \delta$ and $\overline{w^{\prime} b^{\prime}}$ compared to solutions with river forcing, particularly east of the Mississippi River delta and offshore. On the contrary, during summer, seasonal-mean values are larger in solutions with river forcing throughout the entire region. The river effects can be rationalized in terms of scaling arguments that relate submesoscale current magnitudes to the surface boundary layer depth and lateral buoyancy gradients. River outflow enhances submesoscale currents by increasing lateral buoyancy gradients but suppresses them by decreasing the boundary layer depth. A discussion of the submesoscale-generating mechanisms that in each season may determine whether the enhancement effect overcomes the suppression effect or vice versa is presented. Regional comparisons of horizontal velocity spectra, root-mean-square $\zeta$, root-mean-square $\delta$, and root-mean-square $\overline{w^{\prime} b^{\prime}}$ across different resolutions show no sign of convergence even at $150-\mathrm{m}$ horizontal resolution. This demonstrates the numerical challenge of modeling the full range of submesoscale currents.
\end{abstract}

\section{Introduction}

The 2010 Deepwater Horizon oil spill that took place in the DeSoto Canyon region in the northern Gulf of Mexico (GoM) was the largest in history, releasing $\sim 4.4$ million barrels into the ocean (Crone and Tolstoy 2010). This catastrophic event emphasized the urgent need for understanding oceanic dispersion and transport of contaminants that affect coastal ecosystems, economy, and human health. To this end, the Grand Lagrangian

Supplemental information related to this paper is available at the Journals Online website: https://doi.org/10.1175/JPO-D-170035.s1.

Corresponding author: Roy Barkan, rbarkan@atmos.ucla.edu
Deployment (GLAD) experiment took place in the summer of 2012 with the aim of quantifying dispersion statistics from an unprecedented number of deployed drifters (Poje et al. 2014). It was found that ocean currents were locally controlled by eddies on the scale of the dispersing particles' separation (i.e., local dispersion; LaCasce 2008) down to 100-m scales (Poje et al. 2014). The same authors suggested that submesoscale dynamics played a key role in the mixing of contaminants in this region and were responsible for the local dispersion.

Submesoscale currents are typically associated with spatial scales of $O(1-10) \mathrm{km}$, temporal scales of $O$ (days), and are dynamically defined has having $O(1)$ Rossby and Richardson numbers (Thomas et al. 2008). They appear in the form of fronts, filaments, and eddies and are often abundant near the surface of the ocean 
(McWilliams 2016 and references therein). Their significance in affecting near-surface buoyancy and tracer fluxes is well established (Capet et al. 2008); however, their role in surface dispersion of contaminants is relatively less studied.

In the winter of 2016, the Lagrangian Submesoscale Experiment (LASER), which took place in the De Soto Canyon region, was focused on investigating particle dispersion and on studying individual submesoscale features by deploying an even larger number of drifters than during GLAD as well as using ship-based and aerial observations. To accompany LASER, which focused primarily on offshore processes, the Submesoscale Processes and Lagrangian Analysis on the Shelf (SPLASH) took place in the spring of 2017 , focusing on nearshore submesoscale dynamics (for more information on LASER and SPLASH visit http://carthe.org/). These recent experiments provide a large dataset with which to study submesoscale phenomena in the northern GoM and emphasize the need for a high-resolution regional ocean modeling to help plan the experiments and provide spatial and temporal context for the data analysis.

Using submesoscale-permitting numerical simulations, Luo et al. (2016, hereinafter L16) suggested that the primary drivers of submesoscales in the De Soto Canyon region are the Loop Current eddies and the Mississippi-Atchafalaya River system (hereinafter rivers). They further argued that in winter when the mixed layer is deepest, submesoscales are generated primarily by frontogenesis and mixed layer instabilities, whereas during summer they are weaker than in winter and are associated with frontogenesis fueled by the horizontal density gradients induced by the freshwater fluxes of the rivers. Finally, they have shown that during winter submesoscales were confined to the continental slope and offshore regions, whereas during summer they penetrated closer to the shelf.

In this paper and its companions (Barkan et al. 2017, hereinafter Part II; Choi et al. 2017, hereinafter Part III), we extend the work of L16, employing submesoscaleresolving numerical simulations with 3 to 10 times higher resolution. In this first paper, we discuss resolution requirements for submesoscale-resolving simulations, provide statistical analysis of submesoscale currents in the northern GoM during winter and summer, and illustrate the role of the rivers in the generation of submesoscale currents in this region. We carry out two separate sets of experiments, with and without rivers forcing, and analyze the resulting statistically equilibrated solutions (hereinafter With-River and No-River solutions). Both sets of experiments utilize a series of one-way nested grids with horizontal resolution ranging from $5 \mathrm{~km}$ to $150 \mathrm{~m}$ (Fig. 1), as explained in section 2. A validation with respect to observations is provided in section 3. In section 4, we describe the types of submesoscale structures found in the GoM and evaluate how well they are resolved in our solutions. In section 5, we analyze various statistical measures of submesoscale currents and make comparisons between No-River and WithRiver solutions. The comparison is extended in section 6 , where we focus on the differences between nearshore and offshore regions, east and west of the Mississippi River delta (hereinafter the Bird's Foot). In section 7, we provide a dynamical characterization for the effects of the river outflow with respect to scaling theories for submesoscale currents. In section 8 , we summarize the results of the first paper. In Part II, we investigate the rivers' influence on the flow evolution in the northern GoM using temperature-salinity relation analysis and evaluate crossshelf river water transport mechanisms in the Mississippi River jet and west of the Bird's Foot. In Part III, we present an investigation of basic Lagrangian statistics based on the same set of integrations, evaluating the impact of submesoscale currents on surface stirring in the region. $\mathrm{Al}$ though the series of papers are motivated by GLAD, LASER, and SPLASH, the focus in all three parts is on understanding submesoscale processes and modeling constrains rather than on thorough data-model comparison.

\section{Model setup}

Two sets of realistic simulations of the GoM and surrounding region are carried out using the Regional Oceanic Modeling System (ROMS; Shchepetkin and McWilliams 2005). ROMS solves the primitive equations in terrain-following coordinates using the full equation of state for seawater (Shchepetkin and McWilliams 2011). The fundamental difference between the two sets of experiments is the exclusion of the Mississippi-Atchafalaya River system forcing in the second set (No-River solution) compared with the first set (With-River solution), discussed in detail in the subsection below. We utilize a one-way nesting procedure as described in Mason et al. (2010) with successive, nearly isotropic $(d x \approx d y)$ grid resolutions, varying from $\approx 7 \mathrm{~km}$ covering most of the Atlantic Ocean, $\approx 5 \mathrm{~km}$ for the Caribbean Sea and the surrounding region, $\approx 1.5 \mathrm{~km}$ for the GoM, $\approx 500 \mathrm{~m}$ for the northern $\mathrm{GoM}$, and $\approx 150 \mathrm{~m}$ for the De Soto Canyon region, around the location of the Deepwater Horizon spill (Fig. 1). The stretching parameters for all simulations are shown in Table 1. The slight modifications to the stretching parameters in the $1.5-\mathrm{km}$ and $500-\mathrm{m}$ nests compared with the 5- and 7-km nests are aimed at the best resolution of the near-surface dynamics. The stretching parameters of the $150-\mathrm{m}$ nest are designed to best resolve both the near-surface and near-bottom 


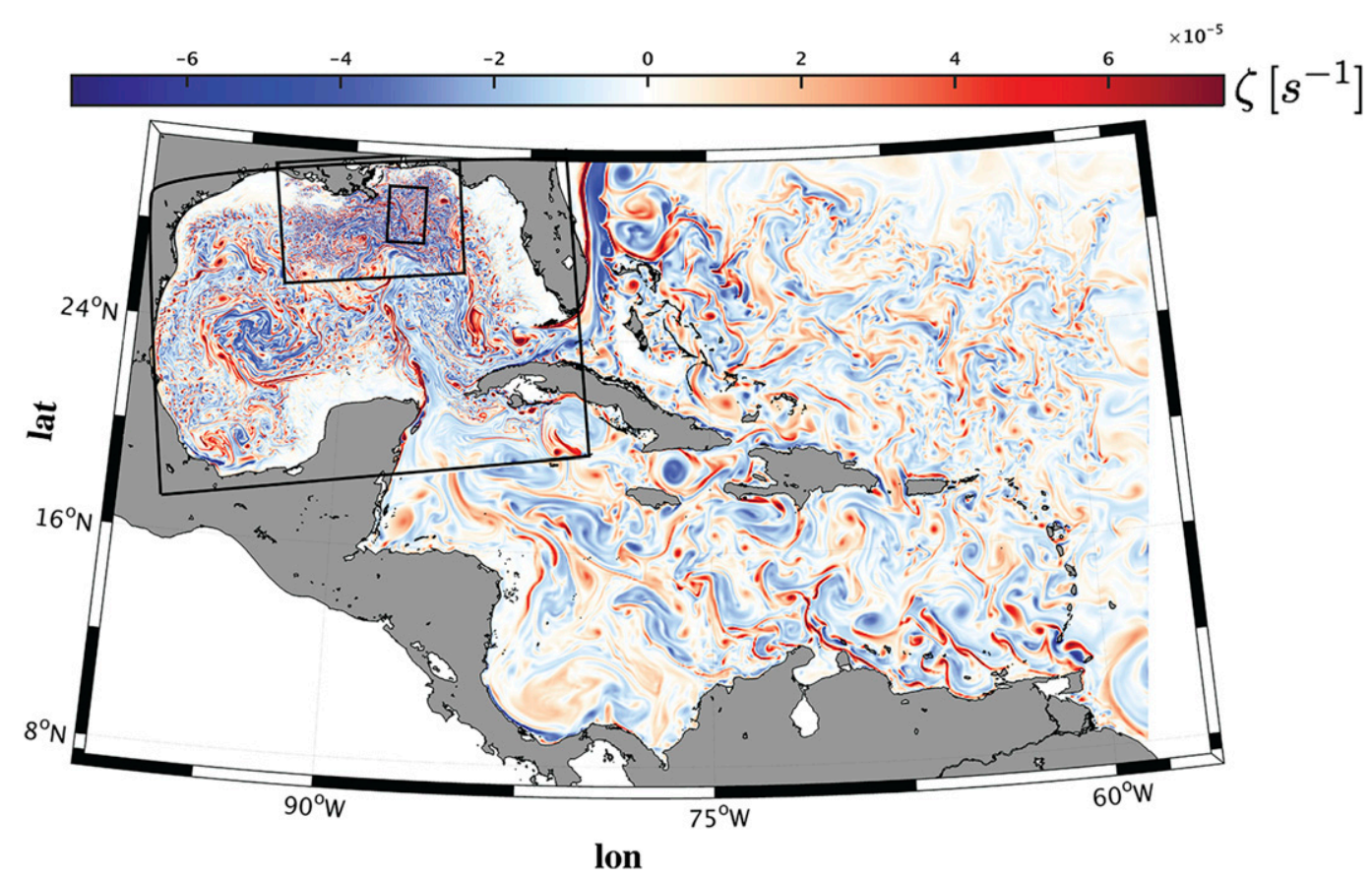

FIG. 1. Vorticity snapshots across the grid nests used in this study. The grid resolutions from the outermost to the innermost nests are $5 \mathrm{~km}, 1.5 \mathrm{~km}, 500 \mathrm{~m}$, and $150 \mathrm{~m}$. The 7-km grid that covers most of the Atlantic Ocean is not shown (see section 2 for details).

boundary layer dynamics. In this manuscript, the focus is on the near-surface dynamics, whereas a thorough investigation of the near-bottom dynamics is left for future work. The last two submesoscale-resolving nests in the With-River solution set were used to help prepare for LASER and proved helpful in illustrating the types of submesoscale features found in the field.

The bathymetry for all domains is constructed from the SRTM30_PLUS dataset (available at http://topex. ucsd.edu/WWW_html/srtm30_plus.html) and is smoothed to avoid aliasing whenever the bathymetric data are available at higher resolution than the computation grid. The boundary conditions for the outermost nest and the surface forcing are climatological for all simulations using the QuikSCAT-based daily product of scatterometer wind stresses (Risien and Chelton 2008), CORE (Large and Yeager 2009) monthly heat flux atmospheric forcing, and HOAPS (Andersson et al. 2010) monthly freshwater atmospheric forcing. A diurnal cycle in the shortwave radiation (heat flux) is also applied based on the sun's angle above the horizon as a function of time, calendar date, and geographical coordinates. Tidal effects, wind-forced inertial motions, and phase-averaged surface wave effects are neglected. Details of the forcing implementation and bathymetric smoothing are described in Lemarié et al. (2012). Vertical mixing of tracers and momentum at the surface and bottom boundary layers is done with the K-profile parameterization (KPP; Large et al. 1994). The bottom friction effect is parameterized using the logarithmic law of the wall with a roughness length of $0.01 \mathrm{~m}$. A third-order, horizontal, upstream-biased advection scheme, which implicitly works as a horizontal mixing parameterization for momenta and tracers, is used and augmented by the vertical, semi-implicit advection scheme discussed in Shchepetkin (2015). For the 7-, 5-, and 1.5-km nests, isoneutral diffusion (Lemarié et al. 2012) is also used.

For the With-River solution set, the initial and boundary information for the outermost Atlantic grid is taken from a monthly Simple Ocean Data Assimilation (SODA; Carton and Giese 2008) climatology based on SODA, version 2.0.4. This outermost solution is spun up from its initial state for 2 years and used to force the $5-\mathrm{km}$ and subsequent nests. For each nest we analyze

TABLE 1. Stretching parameters for the various grids used in this study. All parameters are based on Shchepetkin and McWilliams [2009; (2.2)-(2.4)].

\begin{tabular}{ccccl}
\hline \hline Grid Resolution $(\mathrm{km})$ & $h_{\text {cline }}(\mathrm{m})$ & Number of $\sigma$ levels & $\theta_{s}$ & $\theta_{b}$ \\
\hline 7 & 300 & 50 & 7 & 2 \\
5 & 300 & 50 & 7 & 2 \\
1.5 & 350 & 50 & 8 & 2.5 \\
0.5 & 350 & 50 & 8 & 2.5 \\
0.15 & 300 & 60 & 8 & 6 \\
\hline
\end{tabular}




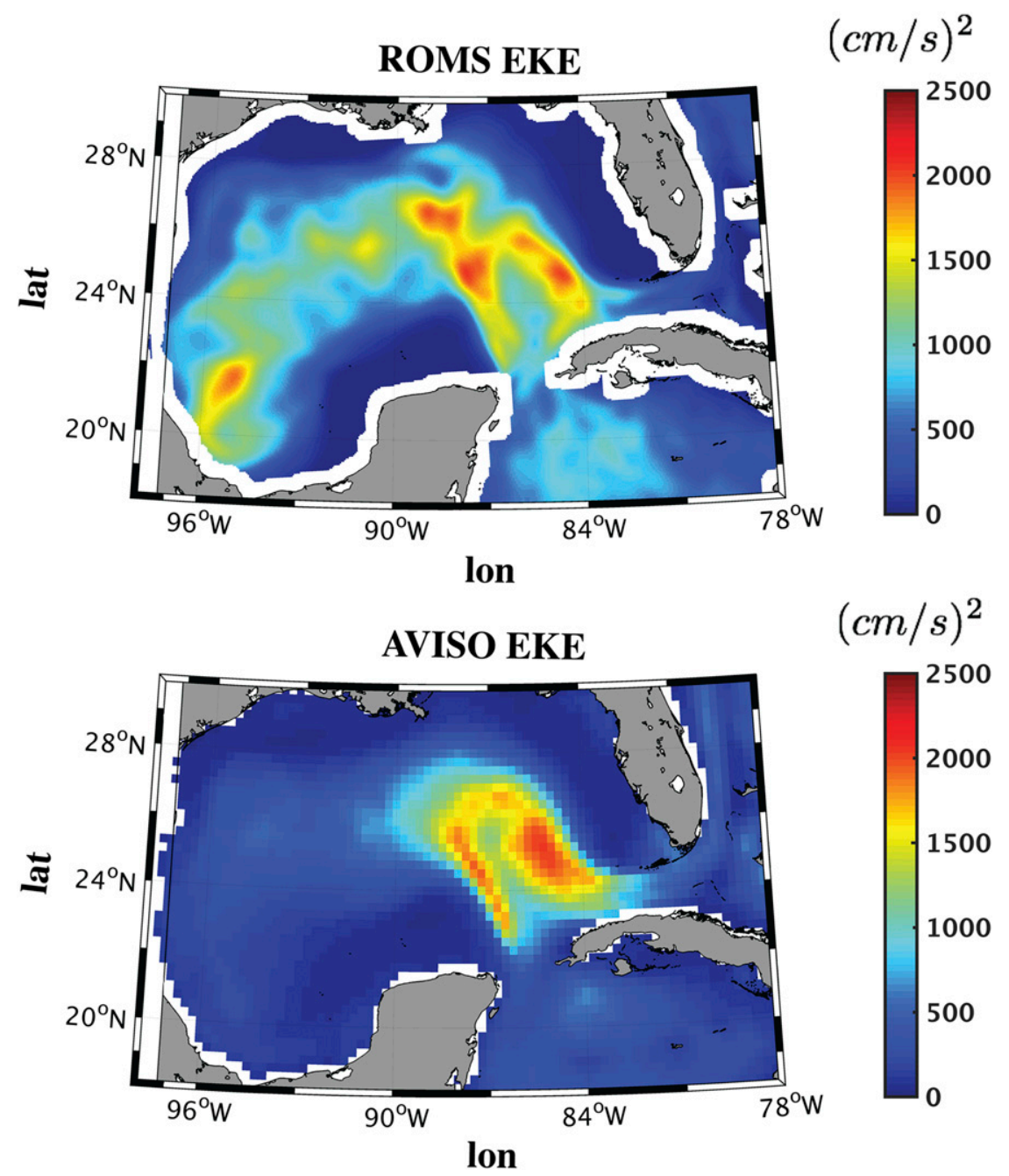

FIG. 2. A comparison between the yearly mean geostrophic EKE in the 5-km model and AVISO. The model EKE was filtered using a spatial Gaussian filter with a standard deviation of $20 \mathrm{~km}$ to approximately match the resolution of AVISO.

1 year after equilibration focusing on winter-averaged (January, February, March) and summer-averaged (July, August, September) quantities. Because the initial conditions for any "child" grid are interpolated from an already equilibrated "parent" solution, the equilibration time is at most one week. The finest $150-\mathrm{m}$ nest is only equilibrated for the month of February, the time during which LASER was conducted. For the analysis that follows, the horizontal velocity field $(u, v)$, sea surface height (SSH), sea surface temperature (SST), sea surface salinity (SSS), and various boundary layer parameters are saved twice a day. The boundary layer parameters are sensitive to the diurnal cycle in heat flux and, as a result, the seasonally mean values presented throughout this paper are subject to aliasing due to the twice per day output frequency. We have tested for aliasing effects by comparing averages between identical solutions with twice per day output frequency and hourly output frequency, and we found biases to be of $O(10 \%)$. A careful analysis of the diurnal cycle in submesoscale currents is deferred to future work however. We note that despite the biases, the differences between the With-River and No-River solutions presented in this paper are robust (see section 6 for standard error estimates). Most of the analysis is carried out on the 500-m nest because it is submesoscale resolving (see the subsection in section 4 for further discussion), while also occupying a domain large enough to allow for a meaningful statistical comparison between different regions.

To simulate the No-River solution set, we first rerun the $5-\mathrm{km}$ nest for 3 years without river forcing, allowing the fresher shelf water to flush out of the basin. We then use the last year of equilibrated 5-km No-River solution and nest down through the $1.5-\mathrm{km}$ grid to the $500-\mathrm{m}$ grid. 


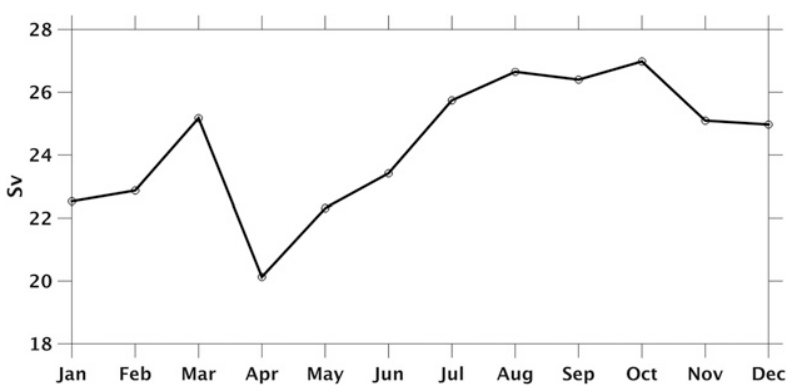

FIG. 3. The 5-km model monthly mean transport across the Yucatan Channel. The annual-mean value is $24.4 \pm 2.1 \mathrm{~Sv}$ compared with the reported observations of $23.8 \pm 3.2 \mathrm{~Sv}$ (Sheinbaum et al. 2002).

\section{River outflow implementation}

To test the role of the rivers in the GoM, we model river outflow at the 7-, 5-, and 1.5-km nests of the WithRiver solutions using the monthly mean volume flux data from Dai and Trenberth (2002). The volume flux of freshwater is converted to an equivalent surface vertical salinity flux that is applied to an area that decays away from the river mouth with a length scale of $100 \mathrm{~km}$. This decay scale ensures that the monthly mean freshwater penetrates far enough offshore. Furthermore, the equivalent surface salinity flux associated with each river is normalized to ensure that the freshwater influx is conserved. In the 500- and $150-\mathrm{m}$ nests, we incorporated daily river volume flux data from the USGS (http://waterdata.usgs.gov/nwis/rt) for the year 2010. The stations associated with the 10 largest river volume fluxes in the northern GoM were used, and, as for the other nests, the corresponding volume flux was converted to an equivalent surface salinity flux with a smaller decay length scale of $15 \mathrm{~km}$. This river implementation and reduced decay scale ensures that the freshwater reaches far enough from the coast while still allowing the resolved fluid dynamics to govern the salinity distribution in the solution. Although the momentum flux associated with the river outflow is neglected, this implementation represents a substantial improvement to L16 in which surface salinity was simply relaxed to the coarse-resolution monthly mean World Ocean Atlas (WOA; Antonov et al. 2009) dataset. Neglecting river momentum flux is probably a reasonable assumption for offshore and well-exposed shelf regions such as around the main Mississippi outflow but may be problematic for the wider shelf to the west where the Atchafalaya River mouth is located.
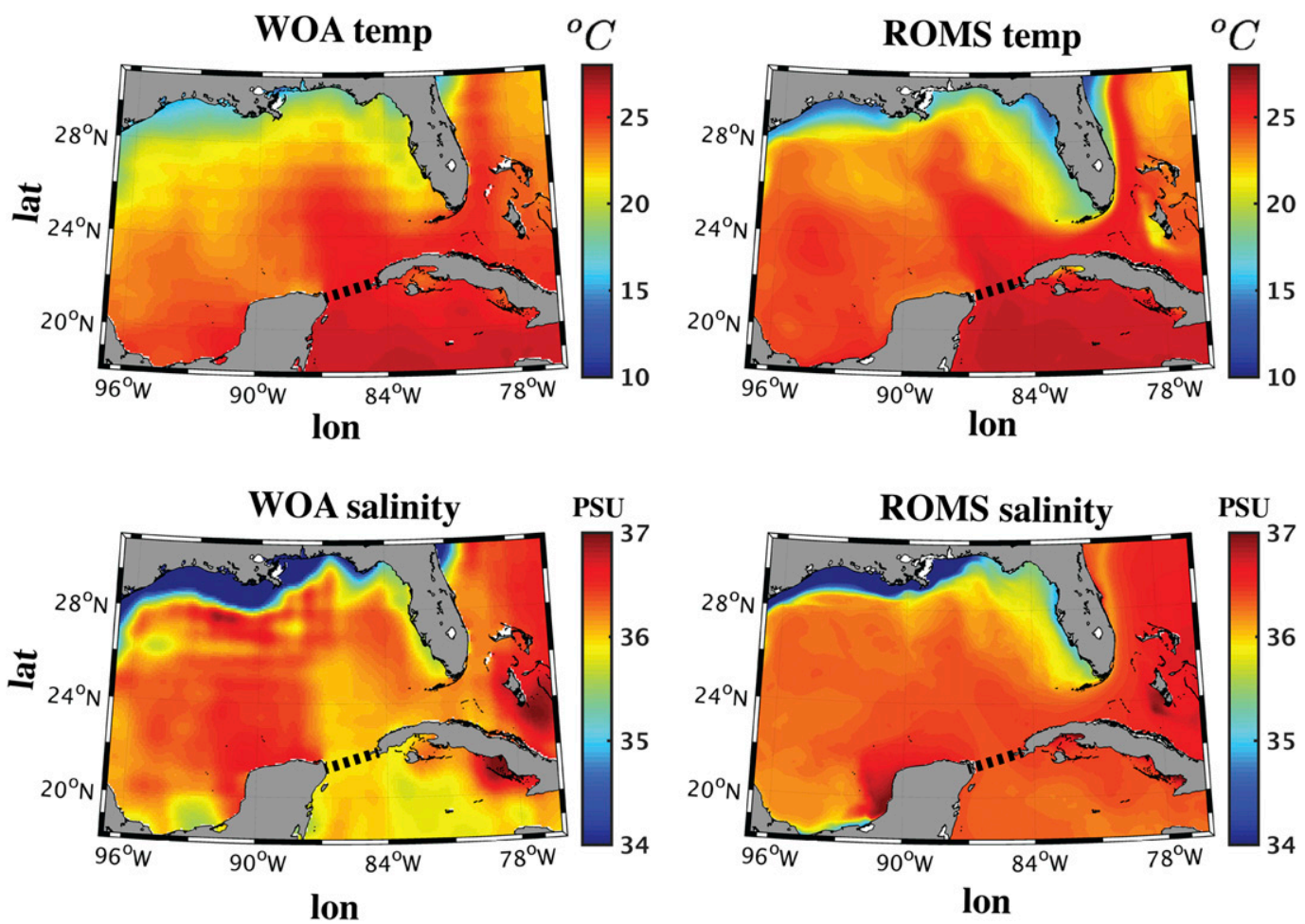

FIG. 4. (top) A comparison between the winter-averaged SST and (bottom) SSS in the 5-km model solution (outermost grid in Fig. 1) and the WOA dataset (Locarnini et al. 2013). The dashed black line indicates the location of the cross section shown in Fig. 5. 

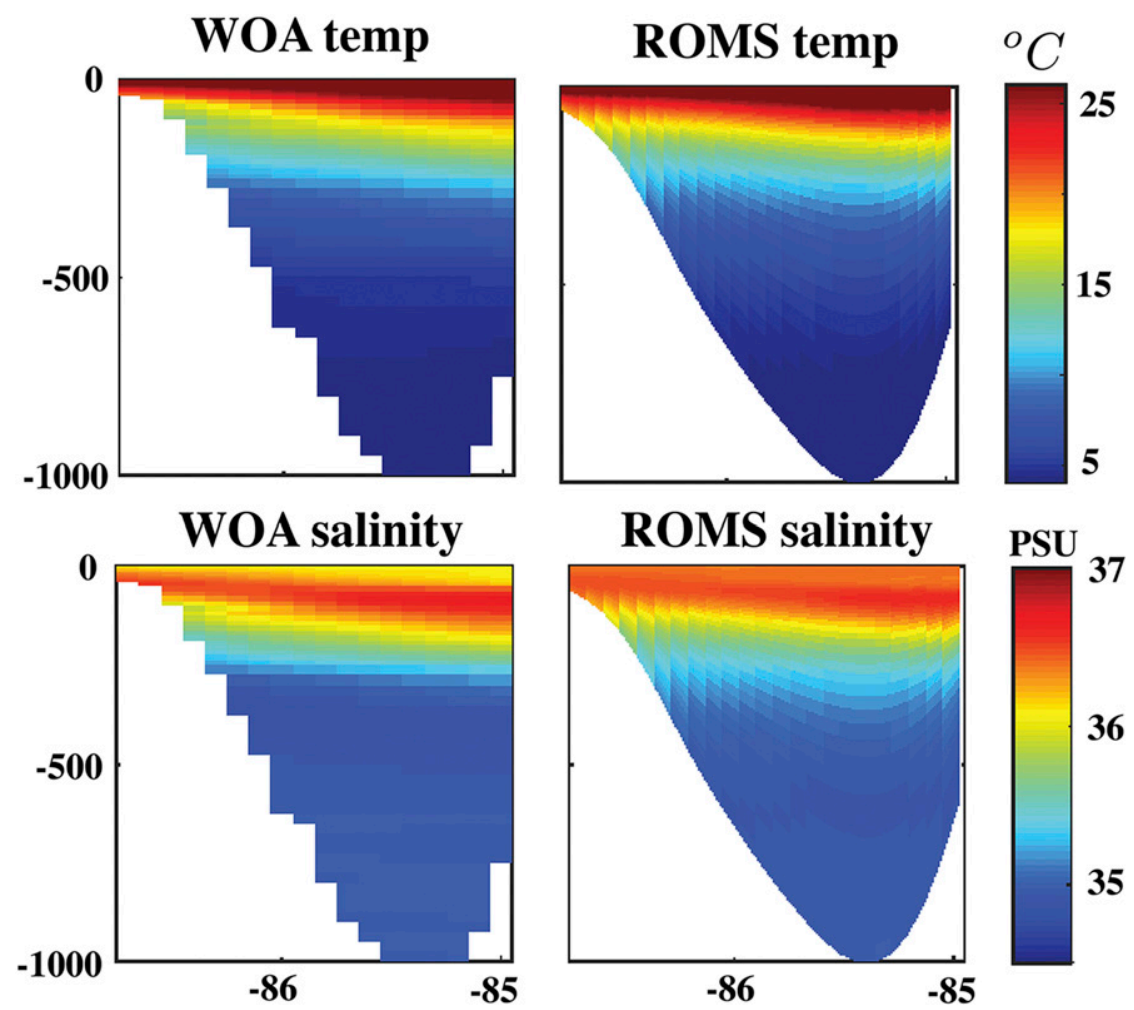

FIG. 5. (top) A comparison between the summer-averaged SST cross section in the Yucatan Channel (dashed black line in Fig. 4) and (bottom) SSS cross section in the Yucatan Channel in the 5-km model solution (outermost grid in Fig. 1) and the WOA dataset (Locarnini et al. 2013).

\section{Model validation}

The climatologically forced solutions presented in this paper are designed to realistically simulate submesoscale processes in the northern GoM; however, the intrinsic model variability and generic forcing allow the match with observations only in a statistical sense. The submesoscale properties we are interested in quantifying are surface intensified (Shcherbina et al. 2013), so we focus our validation primarily on surface quantities. Because the rivers are significant to the dynamics in the GoM, validation is examined with respect to the With-River solution set.

The yearly averaged surface eddy kinetic energy (EKE) in the 5-km solution and AVISO are shown in Fig. 2. The magnitudes are similar in the Loop Current region; however, the model overestimates EKE toward the west of the basin. This EKE overestimate is likely due to the stress formulation of the wind forcing in the model that neglects eddy-current feedback effects (Renault et al. 2016b). The eddy-current feedback induces a surface stress curl opposite to the current vorticity; thereby deflecting energy from the geostrophic current into the atmosphere and reducing EKE (Figs. 6 and 7 in Renault et al. 2016a). A careful investigation of mesoscale variability in the GoM requires much longer integration times and is beyond the scope of this paper (section 5).

The monthly mean transport across the Yucatan Channel in the 5-km solution is shown in Fig. 3. The annual-mean value is $24.4 \pm 2.1 \mathrm{~Sv}\left(1 \mathrm{~Sv}=10^{6} \mathrm{~m}^{3} \mathrm{~s}^{-1}\right)$, which compares well with the reported observations of $23.8 \pm 3.2 \mathrm{~Sv}$ (Sheinbaum et al. 2002). The winter-mean SST and SSS in the model are compared with those of the $1 / 10^{\circ} W O A$ in Fig. 4. There is reasonable agreement in both fields with some differences apparent, particularly with respect to the values very close to the shelf. The model is colder by about $1^{\circ}-2^{\circ}$ and saltier by about 1-2 psu than observations there, ${ }^{1}$ suggesting that the simulations may underestimate the cross-shelf exchange of freshwater (see Part II for an analysis of cross-shelf transport of freshwater), although the biases could also be associated with the high degree of smoothing in the WOA dataset. Similar biases are found in the summer-mean SSS values (not shown), whereas the

\footnotetext{
${ }^{1}$ Note that salinity values close to the shelf are as low as 10 psu.
} 

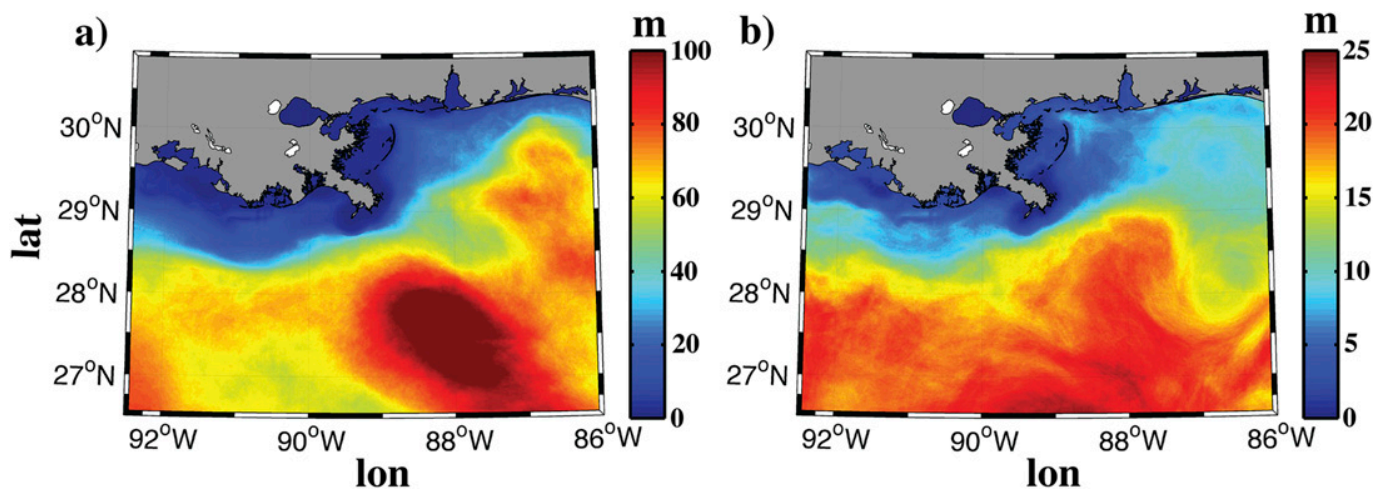

FIG. 6. (a) Winter-mean mixed layer depth and (b) summer-mean mixed layer depth computed using the $0.03 \mathrm{~kg} \mathrm{~m}^{-3}$ density criterion for the $500-\mathrm{m}$ With-River solution.

summer-mean temperature is in better agreement with the WOA dataset than the winter mean. Vertical cross sections of summer-mean salinity and temperature in the Yucatan Channel are shown in Fig. 5. The largest temperature bias is approximately $0.5^{\circ} \mathrm{C}$ in the upper $100 \mathrm{~m}$, where the model is warmer than the WOA dataset. Similarly, the largest salinity bias is approximately 0.3 psu in the upper $100 \mathrm{~m}$, where the model is saltier than the WOA dataset. The biases during winter are of similar magnitudes (not shown). We have examined additional temperature and salinity cross sections and profiles and found them to have a similar shape to those shown in L16, suggesting that the water masses in our model are reasonably consistent with observations.

Submesoscale current magnitudes are sensitive to the mixed layer depth (Boccaletti et al. 2007; Fox-Kemper et al. 2008; McWilliams 2016; section 4); therefore, we compute the winter- and summer-mean mixed layer depths in the 500-m nest (Fig. 6), which is most frequently used for the statistical analysis that follows. We calculated mixed layer depth using both the $0.03 \mathrm{~kg} \mathrm{~m}^{-3}$ density criterion and $0.5^{\circ} \mathrm{C}$ potential temperature at 10-m depth criterion (de Boyer Montégut et al. 2004) and found the results to be similar. The winter-mean and summer-mean values offshore (where the water depth is greater than $500 \mathrm{~m}$ ) are $\sim 73$ and $\sim 19 \mathrm{~m}$, respectively. This is in good agreement, although slightly shallower, than the values reported by Müller-Karger et al. (1991) and Muller-Karger et al. (2015).

The local, scale-dependent dispersion observed during GLAD (Poje et al. 2014) is related to the surface horizontal energy spectra by a simple dimensional analysis. As discussed in LaCasce (2008), local dispersion is expected for slope exponents shallower than -3 , and nonlocal dispersion is expected for slope exponents equal to or steeper than -3 . The meridional-averaged horizontal velocity spectra as a function of zonal wavenumber for the $1.5-\mathrm{km}, 500-\mathrm{m}$, and $150-\mathrm{m}$ nests are shown in Fig. 7. All spectra were computed over the $150-\mathrm{m}$ grid region and time averaged over the month of February. A spectral slope significantly shallower than -3 , typical of surface submesoscales (Capet et al. 2008), is observed for all three solutions, extending to smaller scales as the resolution increases, reaching $\approx 1 \mathrm{~km}$ for the 150 -m solution. This implies that local dispersion behavior in this solution should prevail down to a kilometer scale. Note that the 1.5-km spectral magnitudes are slightly lower than those of the 500 and $150 \mathrm{~m}$, even at larger scales. We associate these differences with the more accurate river implementation (section 2) used for the latter two grids,

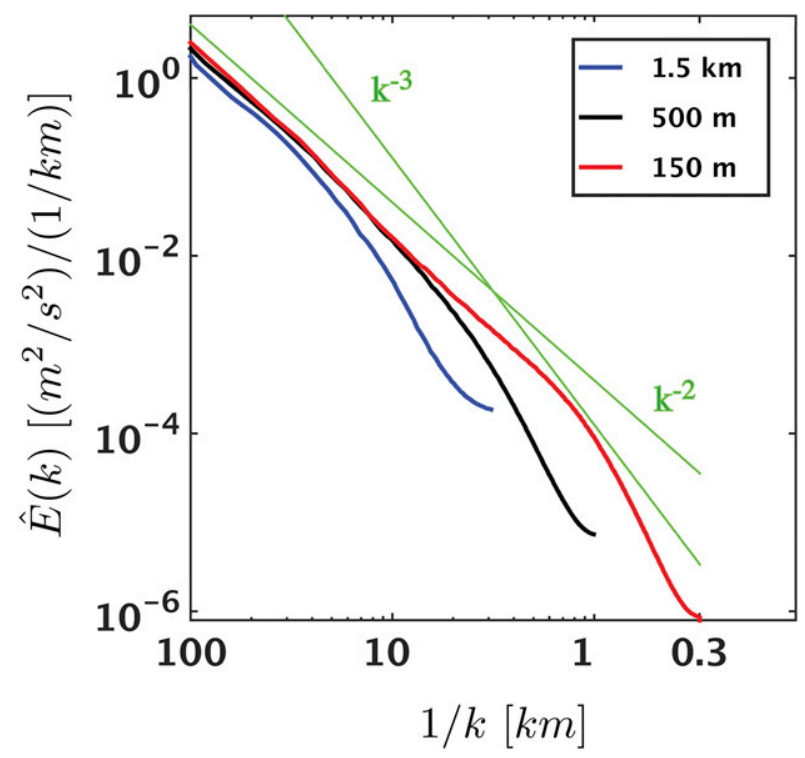

FIG. 7. Meridional-averaged zonal horizontal velocity spectra for the $1.5-\mathrm{km}, 500-\mathrm{m}$, and $150-\mathrm{m}$ With-River solutions, averaged over the month of February in the region covered by the 150 -m grid. The units in the abscissa are effectively in kilometers per cycle. 


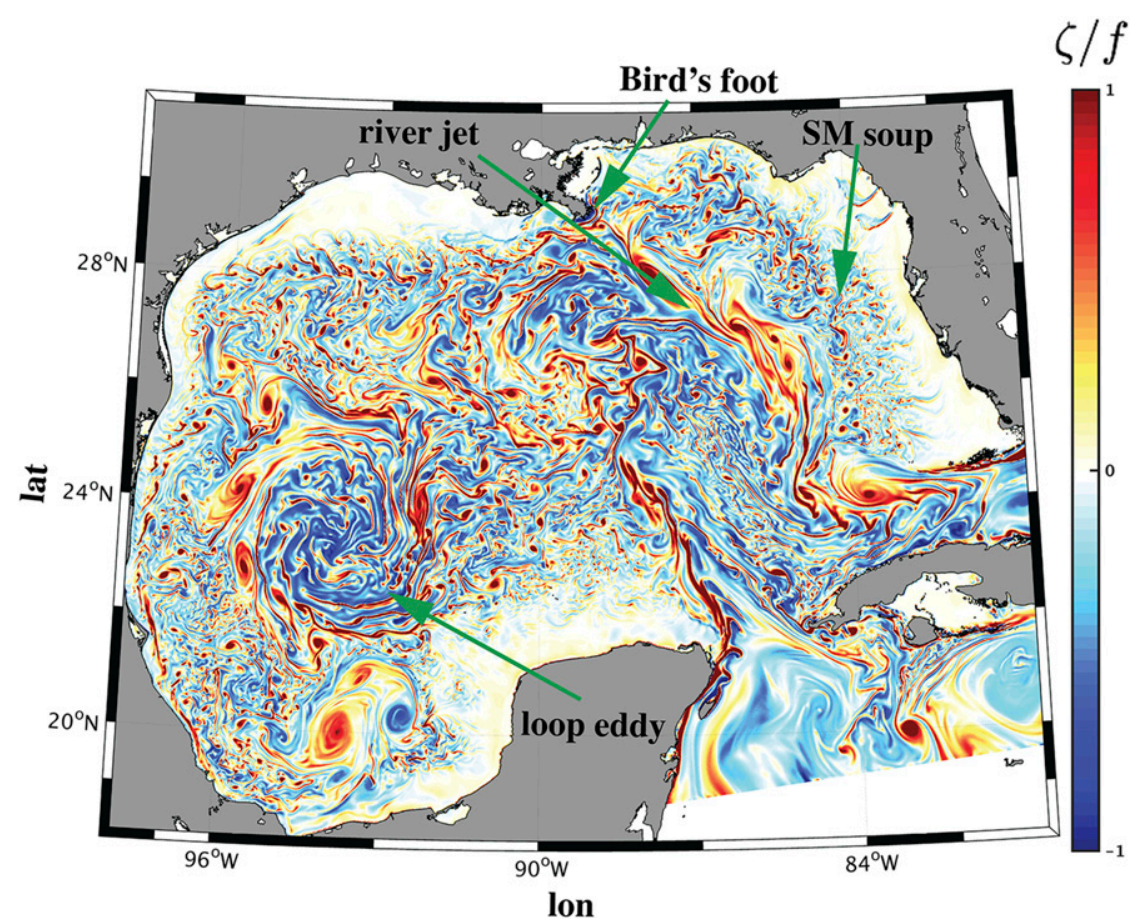

FIG. 8. Snapshot of the vorticity normalized by $f$ during winter from the $1.5-\mathrm{km}$ With-River solution. Green arrows highlight a loop eddy, the Mississippi River front, the submesoscale soup, and the location of the Bird's Foot.

which resulted in a stronger offshore river jet (see Part II for discussion and quantification of the river jet). A thorough analysis of Lagrangian particles in these solutions is presented in Part III.

\section{Submesoscale phenomenology in the GoM}

The variety of submesoscale current structures in the GoM is illustrated in Fig. 8. The first structure to note is the elongated front that is oriented from northwest to southeast starting at the Bird's Foot. We associate this elongated front with the Mississippi River jet, best illustrated in the animation of the surface salinity gradient from the With-River 500-m solution (see the supplemental information). The animation further shows how the nearshore cold and fresh Mississippi River water is diluted and mixed as it is advected to the warmer and saltier water offshore and how temporally and spatially variable the river-forced submesoscale structures are. Recent aerial observations of the Mississippi River jet front (M. J. Molemaker et al. 2017, unpublished manuscript) measure a nearly $2^{\circ}$ temperature change over a few meters, demonstrating how sharp temperature gradients can become in this region.

Additional typical structures to note are the submesoscale fronts and filaments seen in the interior of a loop eddy. Although loop eddies rarely reach as far north as the De Soto Canyon region, they exert a mesoscale straining field that generates submesoscales in the northern GoM.

Finally, throughout the Gulf, in between the larger mesoscale structures, lies the submesoscale "soup" (Shcherbina et al. 2013), consisting of small-scale, fastevolving fronts, filaments, and eddies. The submesoscale soup is only marginally resolved with the $1.5-\mathrm{km}$ grid and is better represented in the finer nests.

The submesoscale-dominated dilution process, the cross-shelf transport mechanisms of the Mississippi River water, and the degree to which the river-forced temperature fronts are compensated by salinity gradients are all discussed in Part II. In Part III, the spatiotemporal variability is thoroughly analyzed from a Lagrangian perspective.

\section{Submesoscale resolution}

The spectral slopes shown in Fig. 7 suggest that the model energy levels at smaller scales have yet to converge, even in the $150-\mathrm{m}$ solution. It is thus crucial to assess the degree to which the solutions presented in this paper accurately model realistic submesoscale currents. To further quantify the level of solution convergence, we compute the root-mean-square (RMS) divergence $\delta=\partial_{x} u+\partial_{y} v$, vorticity $\zeta=\partial_{x} v-\partial_{y} u$, and vertical eddy buoyancy flux $\overline{w^{\prime} b^{\prime}}$ (Table 2), where primes denote 
TABLE 2. RMS divergence $\delta$, vorticity $\zeta$, and buoyancy flux $\overline{w^{\prime} b^{\prime}}$ during February. Values were computed over the $150-\mathrm{m}$ grid region (Fig. 1); $\operatorname{RMS}(\delta)$ and $\operatorname{RMS}(\zeta)$ were computed at the surface, and RMS $\left(\overline{w^{\prime} b^{\prime}}\right)$ was computed at $20-\mathrm{m}$ depth. RMS values for the same region during August were, at most, half of the values in February (not shown).

\begin{tabular}{cccc}
\hline \hline Resolution $(\mathrm{m})$ & $\begin{array}{c}\mathrm{RMS}(\delta) \\
\left(10^{-5} \mathrm{~s}^{-1}\right)\end{array}$ & $\begin{array}{c}\mathrm{RMS}(\zeta) \\
\left(10^{-5} \mathrm{~s}^{-1}\right)\end{array}$ & $\begin{array}{c}\mathrm{RMS}\left(\overline{w^{\prime} b^{\prime}}\right) \\
\left(10^{-7} \mathrm{~W} \mathrm{~kg}^{-1}\right)\end{array}$ \\
\hline 1500 & 1.6 & 3.6 & 1.0 \\
500 & 3.7 & 6.9 & 2.2 \\
150 & 10.0 & 11.0 & 4.0 \\
\hline
\end{tabular}

perturbation from a monthly mean (denoted by bar) during February. Positive, near-surface $\overline{w^{\prime} b^{\prime}}$ values are associated with the conversion of available potential energy (APE) to EKE and are often associated with submesoscale generation (Fox-Kemper et al. 2008). All of the RMS values in Table 2 nearly double with increasing resolution with no indication of convergence. Furthermore, the bulk Rossby number in this region, defined as the ratio between $\operatorname{RMS}(\zeta)$ and the horizontalmean Coriolis frequency $\langle f\rangle=6.9 \times 10^{-5} \mathrm{~s}^{-1}$, increases to $O(1)$ in the 500- and 150-m nests. These $O(1)$ bulk Rossby number values demonstrate (Thomas et al. 2008) the vigorous submesoscale currents found in this region. The RMS values during August for the $1.5-\mathrm{km}$ and $500-\mathrm{m}$ solutions are no more than half of those during February (not shown), illustrating the seasonal cycle in submesoscale current magnitudes. This seasonal cycle is less pronounced than for open-ocean conditions (Mensa et al. 2013; Callies et al. 2015) because of the prominent river-induced submesoscale currents in summer (see sections 5-7).

The lack of solution convergence with respect to these various submesoscale measures raises the question: What does it mean to be submesoscale resolving?

Fox-Kemper et al. (2008) and McWilliams (2016) argue that in order to model submesoscales properly, it is necessary to resolve the mixed layer baroclinic deformation radius:

$$
\begin{aligned}
\mathrm{Rd}_{\mathrm{ML}} & =N_{\mathrm{ML}} h_{\mathrm{ML}} / f \\
& \approx \sqrt{\Delta b_{\mathrm{ML}} h_{\mathrm{ML}}} / f,
\end{aligned}
$$

where $f$ denotes the Coriolis frequency, and $N_{\mathrm{ML}}$ and $h_{\mathrm{ML}}$ denote the surface mixed layer stratification and depth, respectively. Because $N_{\mathrm{ML}}$ is not easily defined in the weakly stratified mixed layer, it can be approximated by $N_{\mathrm{ML}}^{2} \approx \Delta b_{\mathrm{ML}} / h_{\mathrm{ML}}$, where $\Delta b_{\mathrm{ML}}$ is the buoyancy
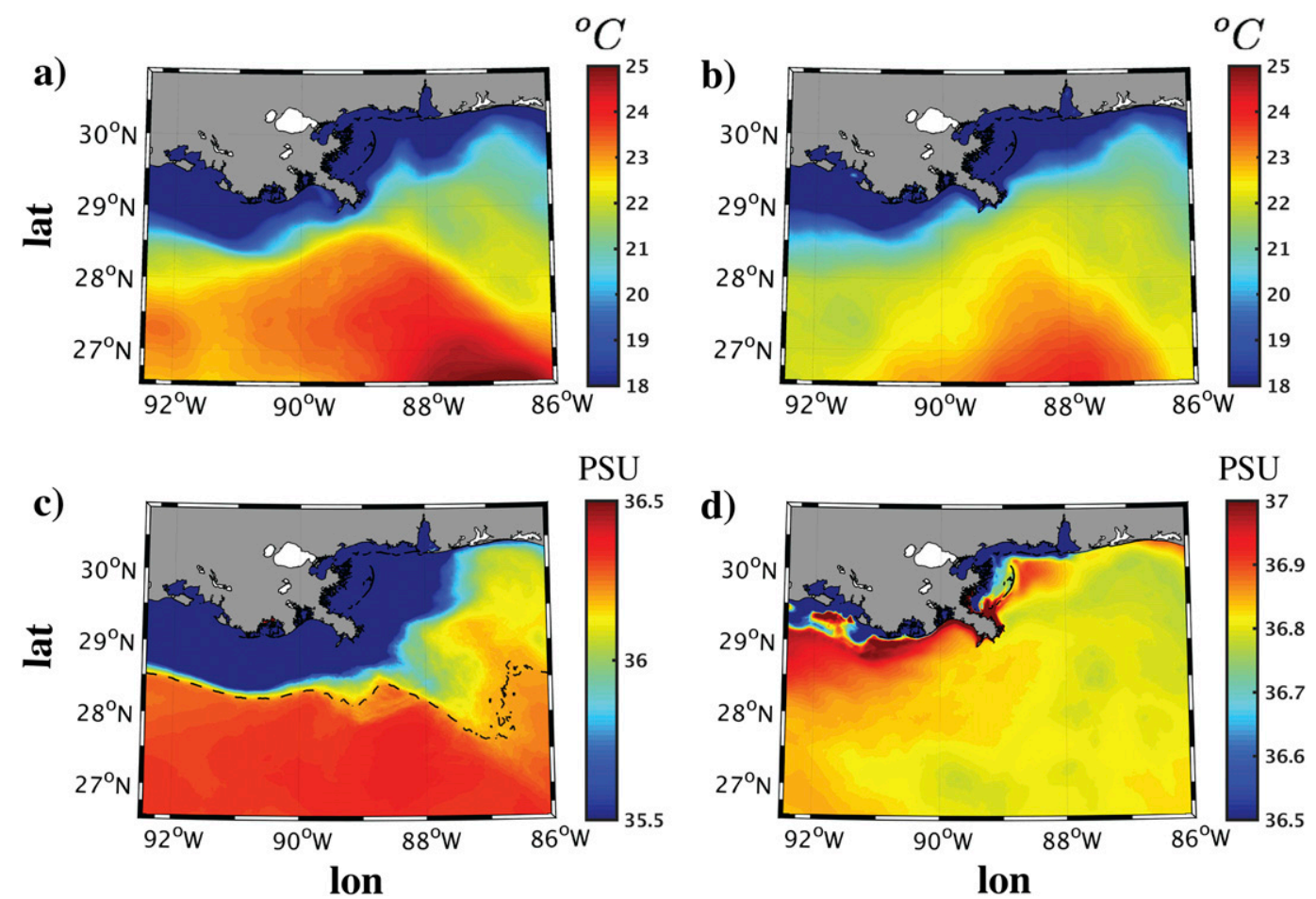

FIG. 9. (a),(b) Winter-mean SST and (c),(d) winter-mean SSS for (left) 500-m With-River and (right) 500-m No-River solutions. Note the different color bar range between (c) and (d). The dashed line in (c) denotes the 36.25-psu salinity contour. 

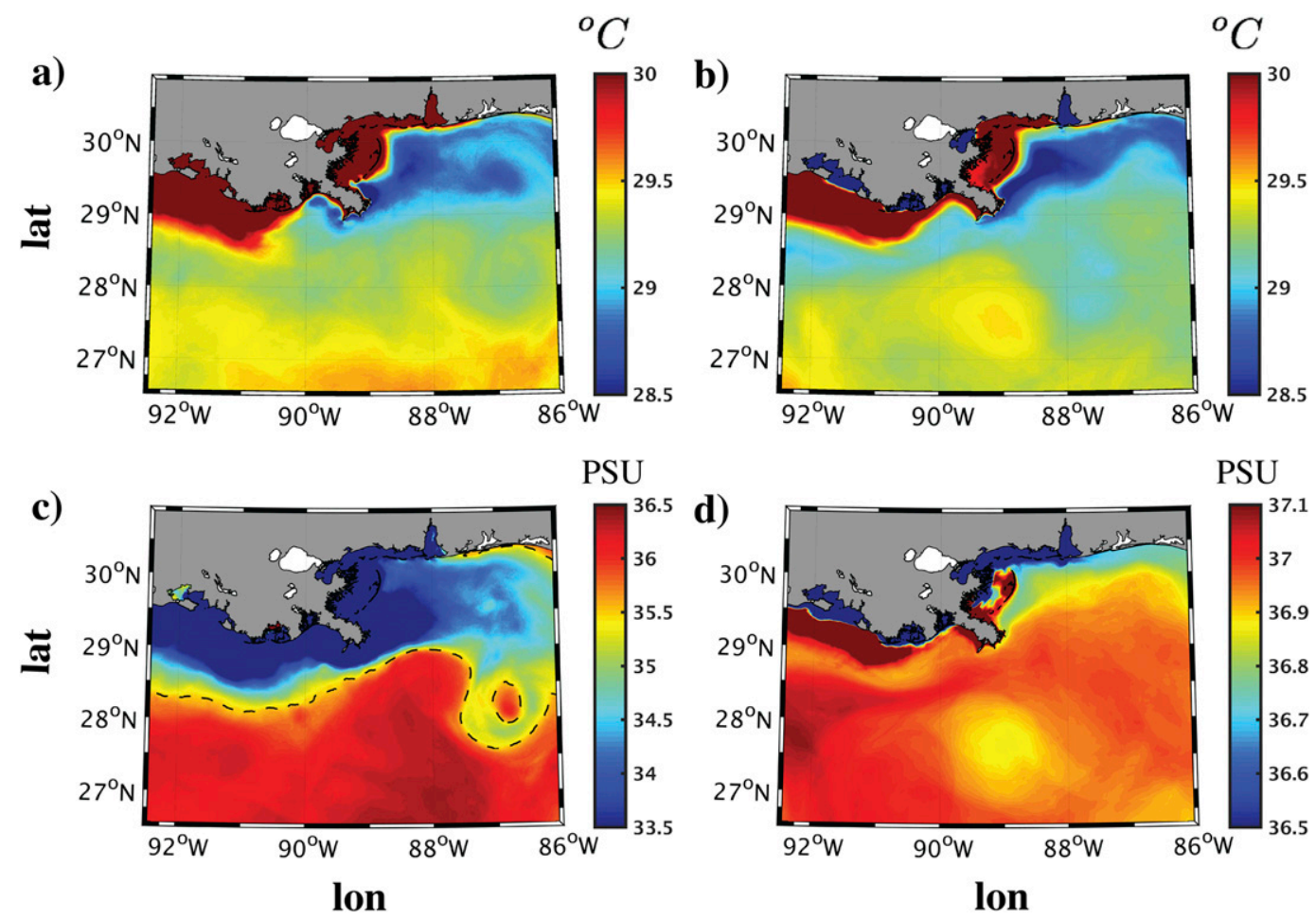

FIG. 10. As in Fig. 9, but for summer. The dashed line in (c) denotes the 35.5-psu salinity contour.

difference across the mixed layer. This leads to the approximate form in (1). Consequently, the mixed layer deformation radius can be estimated from model solutions or observations by assigning to $\Delta b_{\mathrm{ML}}$ the value that corresponds to the temperature or density criterion used to determine $h_{\mathrm{ML}}$. The ad hoc nature of this approximation makes it unclear whether it truly represents the correct mixed layer deformation radius with respect to, for instance, the most unstable mixed layer instability normal mode (Boccaletti et al. 2007). Nevertheless, it suggests that the ratio of mixed layer deformation radii in two distinct regions in the ocean would depend on the ratio of the corresponding mixed layer depths raised to the one-half power. Equation (1) further illustrates that regions and/or seasons with shallow $h_{\mathrm{ML}}$ would require more resolution to adequately model submesoscale currents.

We estimate the mixed layer deformation radii in our $500-\mathrm{m}$ nest based on the $0.03 \mathrm{~kg} \mathrm{~m}^{-3}$ density criterion for $h_{\mathrm{ML}}$ (de Boyer Montégut et al. 2004), which is best suited to the Gulf of Mexico (Muller-Karger et al. 2015), given its typical expansion coefficient values (not shown). The winter-mean mixed layer deformation radii in the With-River solution are 2.2 and $1.1 \mathrm{~km}$ in regions deeper than $500 \mathrm{~m}$ (i.e., offshore) and shallower than $150 \mathrm{~m}$ (i.e., on the shelf), respectively. During summer, as expected, the corresponding shallower mean mixed layer deformation radii are $1 \mathrm{~km}$ and $650 \mathrm{~m}$ offshore and on the shelf, respectively. In the No-River solution, the mixed layer deformation radii are on average larger by a few hundred meters because of the generally deeper boundary layer depths (see section 5a). We cannot quantify how much of the reduction in submesoscale variance is due to seasonality and how much is due to insufficient resolution. Similarly, in both seasons, more resolution would be required to resolve submesoscale activity on the shelf, making it difficult to judge how much of the reduction in submesoscale currents on the shelf, discussed in L16 and section 5 below, is associated with lack of resolution. Settlement of this issue is beyond the scope of this paper (see section 8 for further discussion).

\section{No-River versus With-River solutions}

The role of the Mississippi-Atchafalaya River system in generating submesoscale currents during summer in the northern GoM was first discussed by L16. In their solution, SSS was nudged to the monthly mean WOA values, which, during summer, corresponded to a largescale, shelf-offshore buoyancy gradient. This lateral buoyancy gradient provided the necessary reservoir of APE to generate submesoscale currents broadly distributed across the whole model domain (see section 7 for discussion). Contrary to L16, we account for 


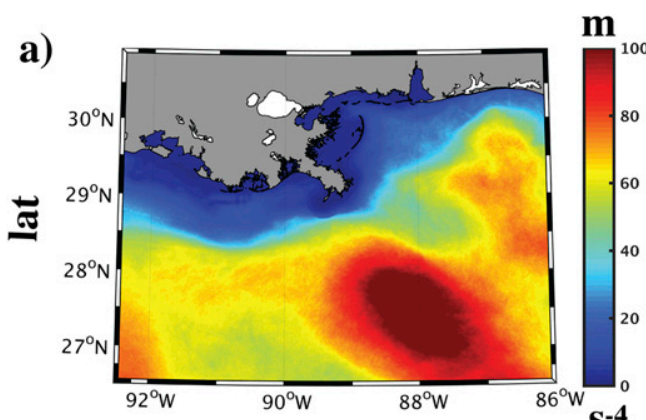

m
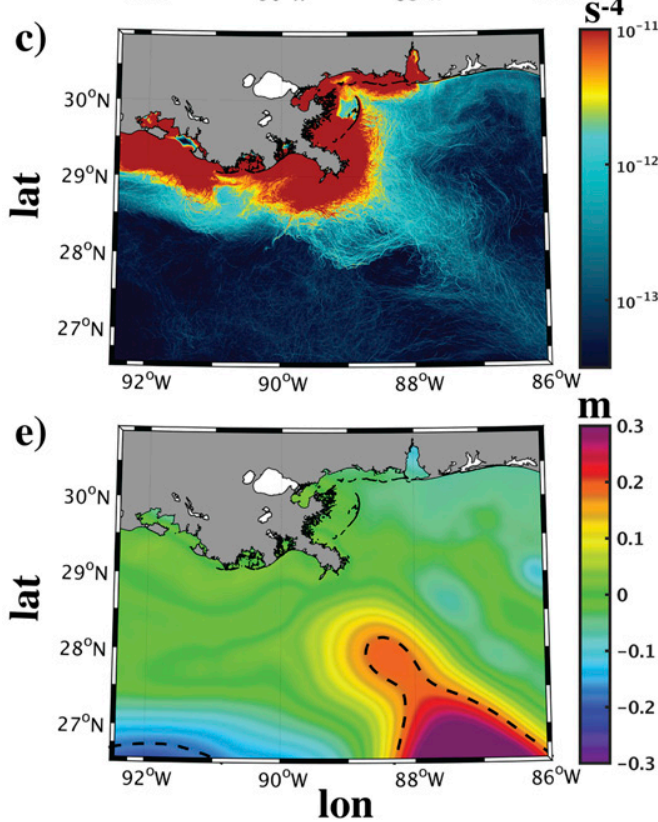

b)

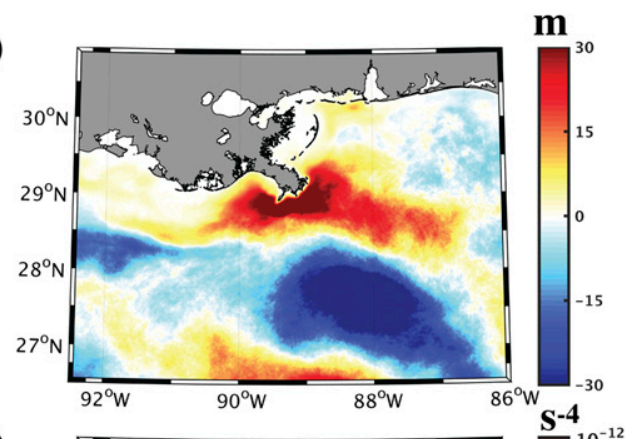

d)

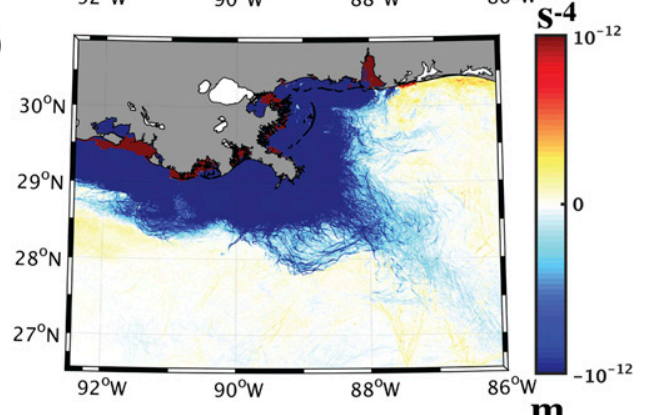

f)

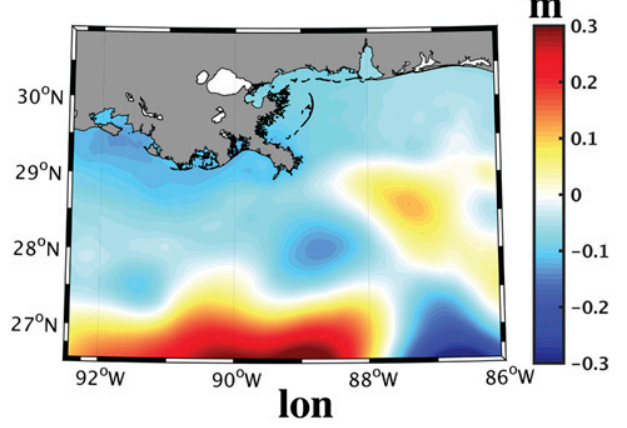

FIG. 11. (a) Winter-mean boundary layer depth, (c) winter-mean $\overline{\left|\nabla_{h} b\right|^{2}}$, and (e) winter-mean $\mathrm{SSH}^{\prime}$, defined as the perturbation from the domain average, for the 500-m With-River solution. (b),(d),(f) The corresponding differences between No-River and With-River solutions. The dashed line in (e) denotes the 0.2- $\mathrm{m} \mathrm{SSH}^{\prime}$ contour.

individual river volume fluxes, and this allows us to better quantify the spatiotemporal role of rivers in generating submesoscale currents. To this end we analyze two sets of solutions with (With-River) and without (No-River) river outflow, focusing on the $500-\mathrm{m}$ solutions that include daily variability in river runoff (see section 2 for details). For reference, the equilibrated winter- and summer-mean SST and SSS are shown in Figs. 9 and 10, respectively. Some SST differences are apparent in both seasons (Figs. 9a,b, 10a,b), but the general spatial distribution is similar. Note that some of the differences can be attributed to the fact that both solutions are associated with distinct realizations of a turbulent flow that can affect, for instance, the number, size, and location of loop eddies within the computational domain. As expected, most of the differences are found in the SSS fields (Figs. 9c,d, 10c,d), where the NoRiver solution is saltier everywhere by about 1 psu (note the different color bar ranges). The fresh SSS very close to the coast in the No-River solution is a result of precipitation patterns that, in this region, are confined to the coast.

\section{a. Surface boundary layer depth, horizontal buoyancy gradient, and sea surface height}

To highlight the differences between the No-River and With-River solutions for any seasonally averaged field $\bar{\psi}$, where $\overline{()}$ denotes a seasonal average, we compare WithRiver solution values with the corresponding relative difference $\bar{\psi}_{\text {No-River }}-\bar{\psi}_{\text {With-River }}$ (right panels in Figs. 11-15).

The surface boundary layer depth $\bar{h}_{\mathrm{BL}}$, as diagnosed from KPP, the surface horizontal (denoted by the subscript $h$ ) buoyancy gradient squared $\overline{\left|\nabla_{h} b\right|^{2}}$, and the mean sea surface height anomaly $\mathrm{SSH}^{\prime}$, defined as perturbation from the domain mean, for the With-River and No-River solutions are shown in Figs. 11 and 12. In winter, the relative difference in $\bar{h}_{\mathrm{BL}}$ of the No-River solution (Figs. 11a,b, 12a,b) is positive in the river 

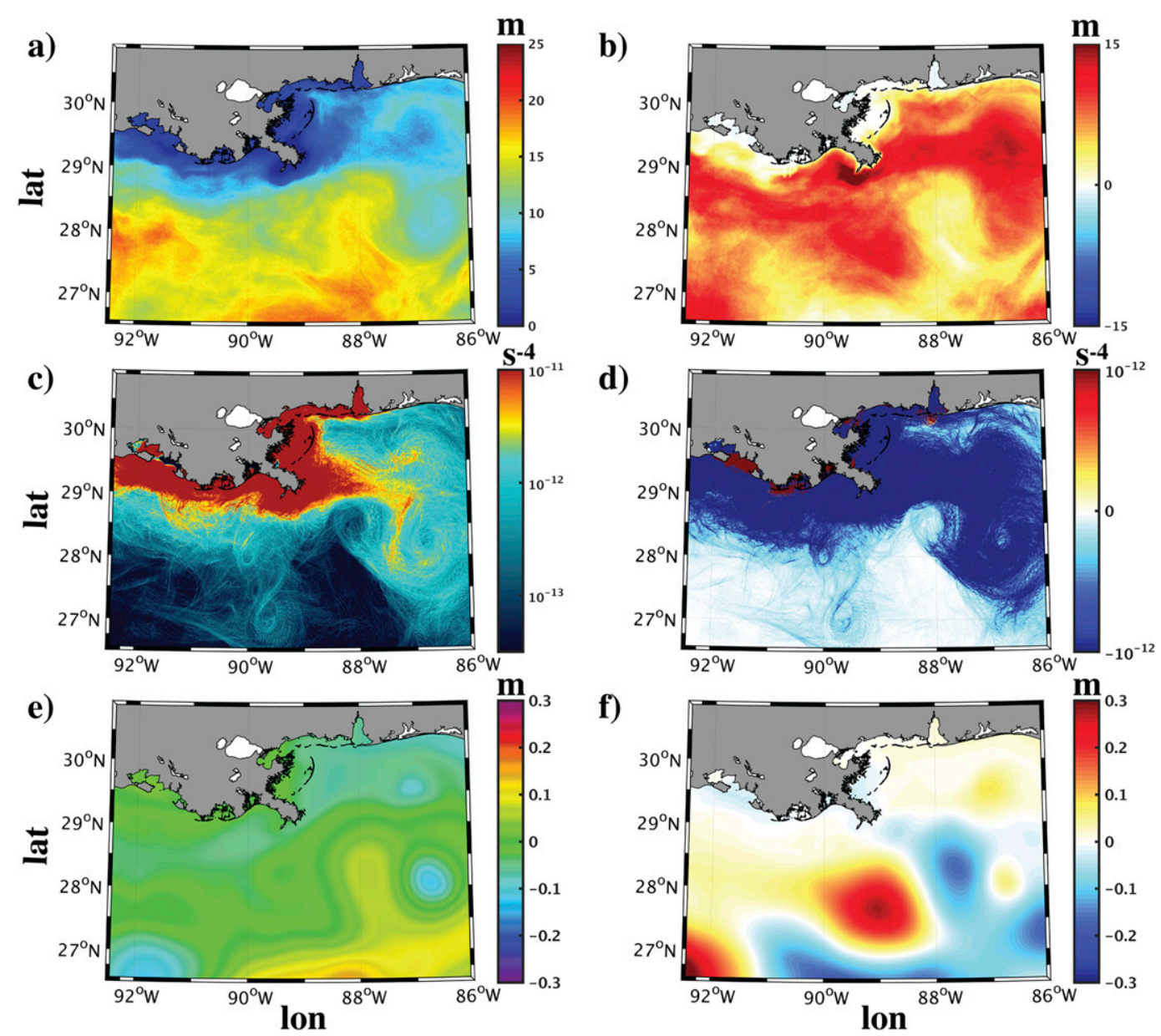

FIG. 12. As in Fig. 11, but for summer. Note the different color bar range in (a) and (b) compared to Fig. 11.

outflow region (the De Soto Canyon region), indicating that $\bar{h}_{\mathrm{BL}}$ would be deeper in this region without river forcing. On the contrary, $\bar{h}_{\mathrm{BL}}$ is shallower farther offshore. The $\mathrm{SSH}^{\prime}$ comparison (Figs. 11e,f) shows a large and positive anomaly in the With-River solution that is associated with the anticyclonic Loop Current eddy. This loop eddy SSH anomaly is much reduced in the NoRiver solution, and it does not reach as far north as in the With-River solution. Because mesoscale eddies are characterized by deep boundary layers, the relative decrease in $\bar{h}_{\mathrm{BL}}$ farther offshore is associated with reduced mesoscale variability there.

The signature of the rivers' outflow is also apparent in the $\overline{\left|\nabla_{h} b\right|^{2}}$ field (Fig. 11c), illustrating its role in driving sharp buoyancy gradients. The negative difference in the NoRiver solution (Fig. 11d) highlights the extent of the rivers' outflow influence.

In summer, $\bar{h}_{\mathrm{BL}}$ is generally much shallower than in winter (note the different color bar range in Figs. 11a and 12a) and everywhere deeper for the No-River solution, with the largest relative differences in the rivers' outflow regions. The $\overline{\left|\nabla_{h} b\right|^{2}}$ has similar magnitudes to those found in winter and is everywhere smaller in the No-River solution without any clear signature of the river outflow. The SSH anomaly in the With-River solution is reduced compared to winter and is again quite different in the NoRiver solution. This further highlights that the mesoscale circulations differ in the two numerical realizations.

\section{b. Surface divergence and vorticity}

Submesoscale currents are characterized by large values of vorticity and horizontal divergence (Thomas et al. 2008; Capet et al. 2008), and we therefore aim to quantify their sensitivity to changes in river forcing as well as determine whether one of the two provides a better characterization of the resulting submesoscale circulations.

Spatial maps of temporal variance of surface divergence $\overline{\delta^{2}}$ and vorticity $\overline{\zeta^{2}}$ during winter and summer are shown in Figs. 13 and 14, respectively. In winter, the rivers' footprint is seen in both variance fields (cf. Figs. 13a,c with Fig. 11c). In addition, a clear reduction in variance magnitudes is observed when 

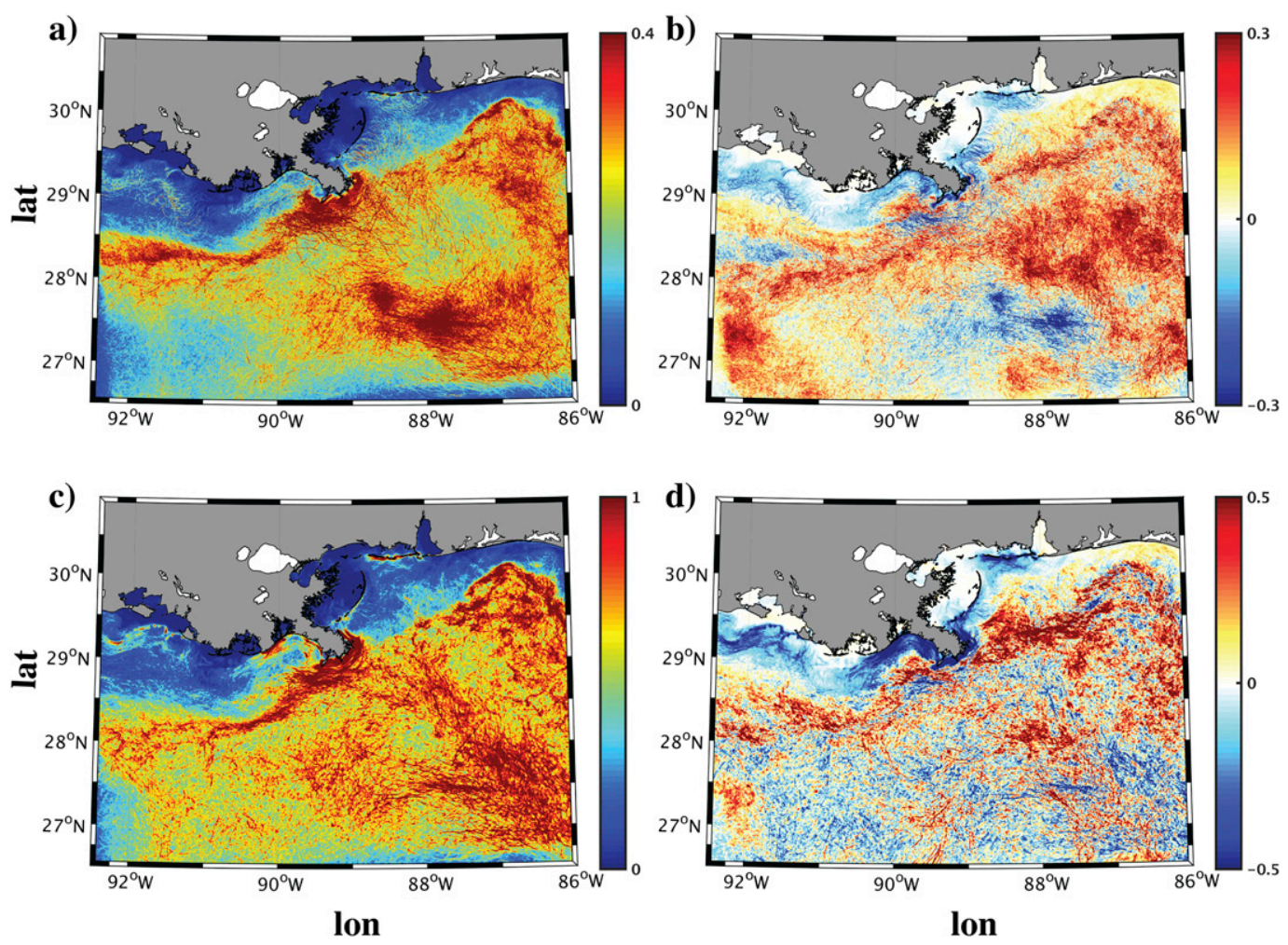

FIG. 13. (a) Temporal variance during winter for divergence normalized by $f$ and (c) for vorticity normalized by $f$ in the 500-m With-River solution. (b),(d) The corresponding differences between No-River and With-River solutions.

approaching the shelf, in agreement with L16, although they do not vanish completely. The relative difference in divergence variance is mostly positive for the NoRiver solution aside from a narrow strip on the shelf in the center and toward the west of the domain. The relative difference in vorticity variance is somewhat similar, although the magnitudes are generally weaker and more negative offshore. This implies that during winter submesoscale currents would generally be stronger in the absence of river outflow.

During summer, the rivers' footprint is still visible in the variance fields; however, the magnitudes are substantially smaller than in winter (note the different color bar range in Figs. 13a,c and 14a,c), demonstrating the reduction in submesoscale activity discussed in section 4 . Contrary to winter, the magnitude reduction over the shelf is less pronounced. Furthermore, the relative difference in the No-River solution is mostly negative, indicating that during summer rivers play an important role in the generation of submesoscales.

\section{c. APE to EKE conversion}

The generation of surface submesoscale currents can result from a number of processes, such as mixed layer eddies, frontogenetic strain, and boundary layer turbulence (see Fox-Kemper et al. 2008; McWilliams 2016; and the subsection in section 7 below). In all cases APE is converted to EKE, and so $\overline{w^{\prime} b^{\prime}}$ is expected to be positive. The $\overline{w^{\prime} b^{\prime}}$ computed in the surface boundary layer is shown in Fig. 15. Values were computed at 20-m depth during winter and at 5-m depth during summer to account for the shallower boundary layer depth in summer, to measure the conversion rate in the interior of the boundary layer (where the vertical velocity is larger than at the surface), and to capture the subsurface signal as close as possible to shore. Although $\overline{w^{\prime} b^{\prime}}$ may be sensitive to the depth at which it is computed, we have experimented with additional depths to establish that differences between winter and summer values are associated with the seasonal change and not the depth at which they are computed. In both seasons the values are nearly everywhere positive, indicating a conversion from APE to EKE, implying the generation of submesoscales. In agreement with Figs. 13 and 14, the magnitudes are generally smaller during summer. Furthermore, the conversion is amplified/reduced in the No-River solution during winter/summer, respectively. 

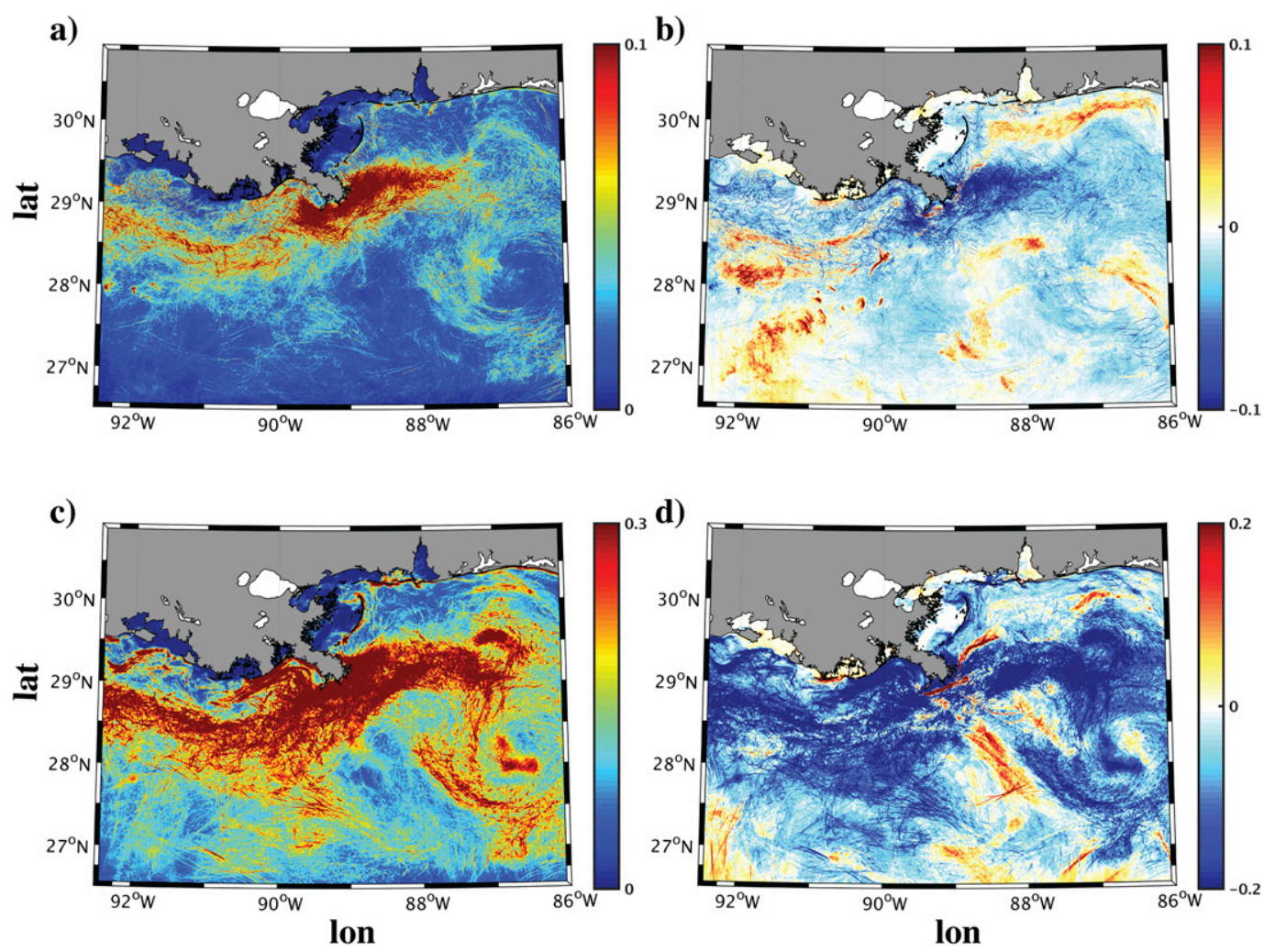

FIG. 14. As in Fig. 13, but for summer. Note the different color bar ranges in all panels compared to Fig. 13.

\section{Geographical differences}

The spatial maps displayed in the previous section (Figs. 11-15) show a difference in submesoscale current magnitudes between shelf and offshore regions. In addition, the clear signature of the Mississippi River plume suggests there will be a difference between regions east and west of the Bird's Foot. Furthermore, the recent SPLASH experiment took place on the shelf just west of the Bird's Foot, and it is therefore instructive to compare it to the shelf to the east. To quantify the spatial inhomogeneity of submesoscale currents in the northern GoM, we decompose the 500-m domain into four regions, shown in Fig. 16. The RMS values of $\zeta / f$ and $\delta / f$ in the four regions are shown in Table 3. Note that most of the values reported are within the standard errors, based on the stringent constraints used to define them (see caption of Table 3). Nevertheless, all of the trends discussed below are consistent if (for example) temporal subsampling is done. Overall, RMS values in winter are larger than in summer and RMS values offshore are larger than on the shelf, in agreement with Figs. 13 and 14.

In winter, the main differences are with respect to RMS divergence values, which are larger everywhere in the No-River solution with the most significant relative change found to the east of the Bird's Foot. This implies that the river outflow inhibits submesoscale generation during winter, particularly to the east of the Bird's Foot, in agreement with Figs. 13a, 13b, and 15a.

On the contrary, in summer, the main differences are with respect to RMS vorticity values that are everywhere larger in the With-River solution compared with the No-River solution. This suggests that rivers enhance submesoscale generation during summer, as previously suggested by L16 and by Figs. 13c, 13d, and 15b.

The PDFs of surface $\delta / f$ normalized by $\operatorname{RMS}(\delta / f)$ on and off the shelf during winter and summer are shown in Fig. 17. The RMS normalization emphasizes statistical differences that are not associated with changes in variance. We do not distinguish between east and west regions (Fig. 16) because the essence of the variability is captured by the RMS values shown in Table 3. In both seasons the PDFs are skewed toward negative values (convergence) with summer PDFs generally less skewed than winter ones. This skewness toward convergence is indicative of frontogenetic processes (Barkan et al. 2017, manuscript submitted to Geophys. Res. Lett.).

The PDFs of surface $\zeta / f$ normalized by $\operatorname{RMS}(\zeta / f)$ (Fig. 18) are positively skewed in both seasons, as 

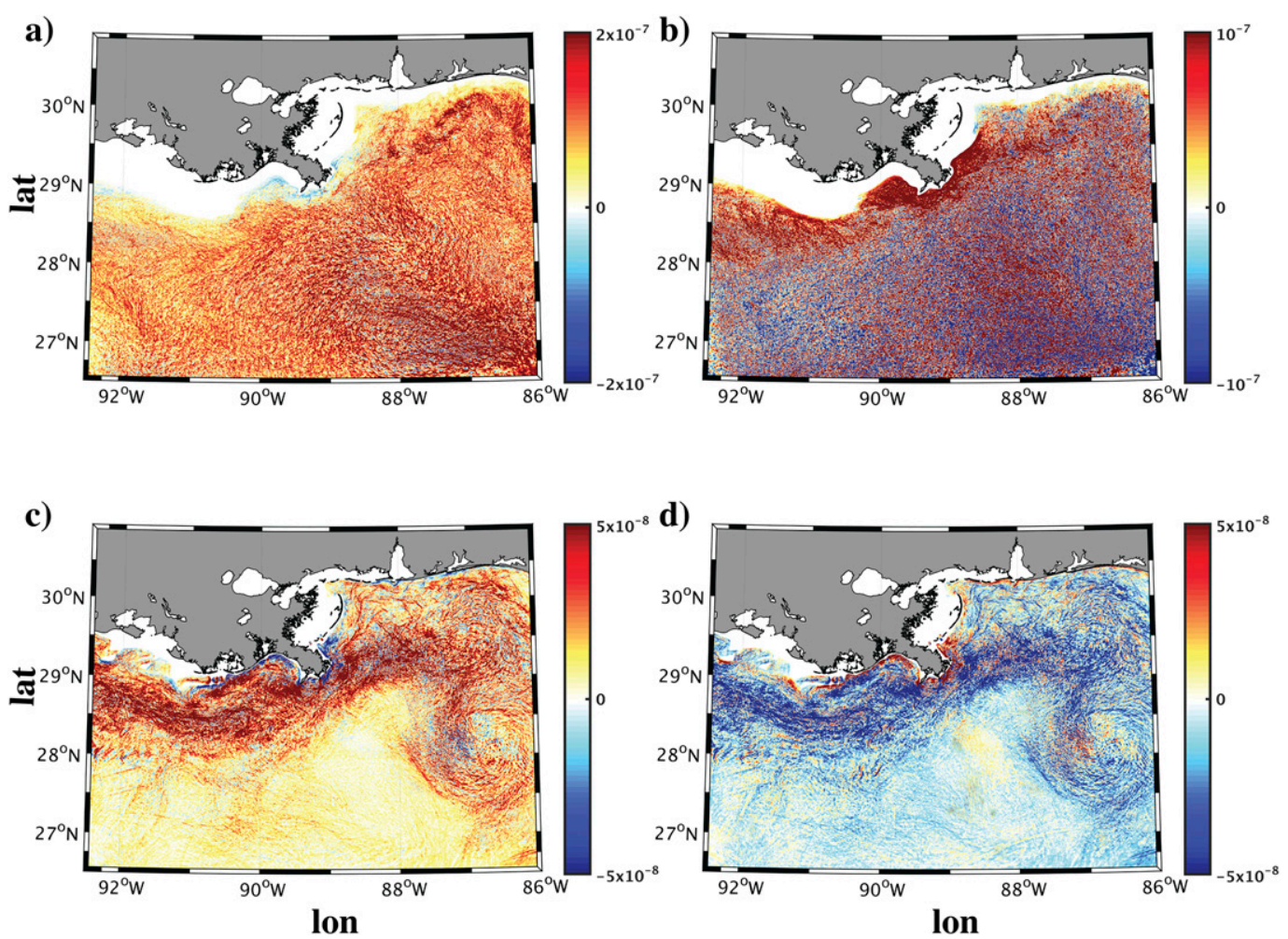

FIG. 15. (a) The $\overline{w^{\prime} b^{\prime}}$ for the 500-m With-River solution at 20-m depth during winter and (c) at 5-m depth during summer. (b),(d) The corresponding differences between No-River and With-River solutions. Note the different color bar range between top and bottom panels.

expected in the presence of submesoscale circulations from previous modeling (Capet et al. 2008) and observational (Shcherbina et al. 2013) results. Some differences between With-River and No-River solutions are found offshore during summer and on the shelf during winter, where, in both cases, negative vorticity values are found more frequently in the With-River solution. However, overall, the With-River and NoRiver PDFs are quite similar in all cases, illustrating that the river forcing has little effect over the skewness and kurtosis.

\section{Discussion}

The geographical characterization presented in sections 5 and 6 is advantageous when trying to compare with observational campaigns that are confined to a specific location. In this section, we aim to describe and quantify, more generally, the role of river forcing in the generation of submesoscale currents. Using SSS and SSH thresholds we extend the information provided in Table 3 and compute $\operatorname{RMS}(\zeta / f)$ and $\operatorname{RMS}(\delta / f)$ in flow regions that are dynamically linked to the river outflow and have weak mesoscale variability (Table 4). Based on
Figs. 9 and 10, we picked salinity values lower than 36.25 psu during winter and 35.5 psu during summer in the With-River solution to define flow regions that are influenced by the river outflow. We then used these salinity-determined flow regions in every snapshot to compute the same statistics in the No-River solution. Similarly, based on Figs. 11 and 12, we picked SSH anomaly magnitudes less than $0.2 \mathrm{~m}$ to define flow regions with weak mesoscale variability. Note that although the mean SSH anomaly magnitude during summer is smaller than $0.2 \mathrm{~m}$ (Fig. 10e), individual snapshots did exhibit anomalies larger than the 0.2-m threshold. This selection methodology allowed us to better evaluate river-induced submesoscale currents in the two solutions while excluding mesoscale-dominated regions. We computed $\operatorname{RMS}(\zeta / f)$ and $\operatorname{RMS}(\delta / f)$ using different thresholds and found that the RMS values were not sensitive to the threshold used. Table 4 generally confirms the results shown in Table 3 and supports the finding that river outflow marginally suppresses submesoscale current generation during winter and substantially enhances it during summer, relative to the NoRiver case. Interestingly, the increase in submesoscale variability during winter in the No-River solution is more 


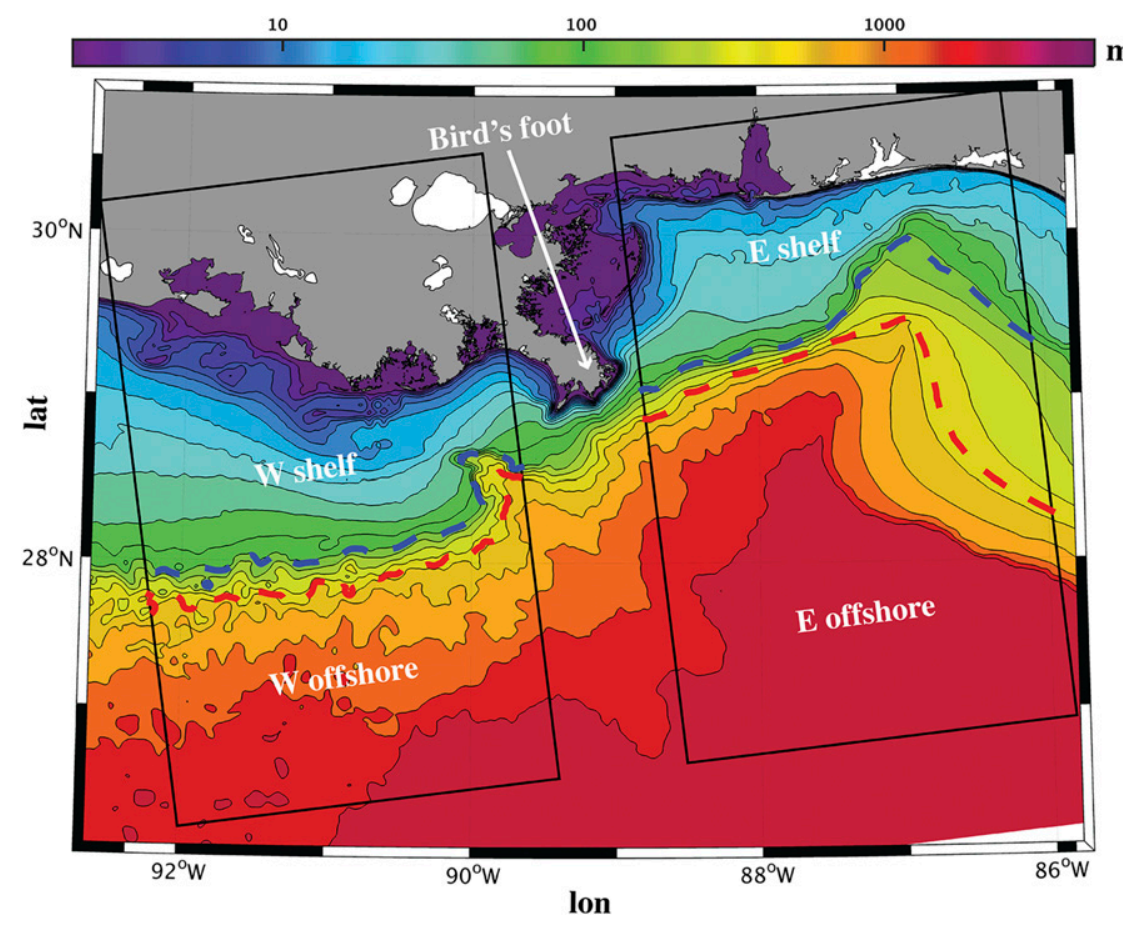

FIG. 16. Bathymetry in the 500-m solution. Solid rectangles denote the eastern (E) and western (W) regions used for the PDF analysis. Dashed blue lines denote the $150-1500-\mathrm{m}$ contour lines, respectively. Shelf regions are defined as shallower than $150 \mathrm{~m}$. Offshore regions are defined as deeper than $500 \mathrm{~m}$. Color bar is in log scale.

significant in horizontal divergence statistics, whereas the reduction during summer is more significant in vorticity statistics. It is possible to establish a direct link between convergent motions of anisotropic submesoscale currents and frontogenesis (Barkan et al. 2017, manuscript submitted to Geophys. Res. Lett.); however, it is unclear which of the fields provides a better characterization for river-forced submesoscale currents or, more generally, for submesoscale turbulence dynamics.

\section{Generation processes for submesoscale currents}

To better understand the effects of the river's forcing on submesoscales in the northern GoM, we examine the following previously proposed scaling theories for the ageostrophic secondary circulation streamfunction $\phi$ and APE to EKE conversion $\overline{w^{\prime} b^{\prime}}$ (McWilliams 2016 and references therein):

$$
\begin{gathered}
\phi_{\mathrm{MLE}} \sim \frac{h_{\mathrm{BL}}^{2}\left|\nabla_{h} b\right|}{f}, \overline{w^{\prime} b^{\prime}}{ }_{\mathrm{MLE}} \sim \frac{h_{\mathrm{BL}}^{2}\left|\nabla_{h} b\right|^{2}}{f}, \\
\phi_{\text {STRAIN }} \sim \frac{\gamma}{f} \phi_{\mathrm{MLE}}, \overline{w^{\prime} b^{\prime}}{ }_{\mathrm{STRAIN}} \sim \frac{\gamma}{f} w b_{\mathrm{MLE}}, \\
\phi_{\mathrm{TTW}} \sim \frac{\left|u_{*}\right| h_{\mathrm{BL}}\left|\nabla_{h} b\right|}{f^{2}}, \overline{w^{\prime} b^{\prime}}{ }_{\mathrm{TTW}} \sim \frac{\left|u_{*}\right| h_{\mathrm{BL}}\left|\nabla_{h} b\right|^{2}}{f^{2}},
\end{gathered}
$$

where $h_{\mathrm{BL}}$ is the surface boundary layer depth, $\left|\nabla_{h} b\right|$ is surface buoyancy gradient magnitude, $\gamma$ is the large-scale geostrophic strain rate, and $\left|u_{*}\right|$ is surface frictional velocity magnitude. The term $\phi_{\mathrm{MLE}}$ is the secondary circulation associated with mixed layer eddies (Fox-Kemper et al. 2008), $\phi_{\text {STRAIN }}$ is the secondary circulation associated with large-scale straining motions, and $\phi_{\text {TTW }}$ is the secondary circulation associated with boundary layer

TABLE 3. Root-mean-square normalized divergence RMS $(\delta / f)$ and vorticity $\operatorname{RMS}(\zeta / f)$ in the regions shown in Fig. 16 for the With-River and No-River solutions. Maximal RMS standard errors are 0.04 for $\operatorname{RMS}(\delta / f)$ and 0.08 for $\operatorname{RMS}(\zeta / f)$ and never exceed $10 \%$ of the signal, where the number of degrees of freedom is based on an assumed decorrelation time scale of 3 days and an assumed decorrelation length scale of $10 \mathrm{~km}$.

\begin{tabular}{lcccccc}
\hline \hline \multirow{2}{*}{ Region, season } & \multicolumn{2}{c}{$\operatorname{RMS}(\delta / f)$} & & \multicolumn{2}{c}{$\operatorname{RMS}(\zeta / f)$} \\
\cline { 2 - 3 } \cline { 5 - 6 } \cline { 5 - 6 } W & With-River & No-River & & With-River & No-River \\
E shelf, winter & 0.39 & 0.40 & & 0.54 & 0.52 \\
W offshore, winter & 0.40 & 0.45 & & 0.56 & 0.60 \\
E offshore, winter & 0.44 & 0.50 & & 0.72 & 0.69 \\
W shelf, summer & 0.21 & 0.63 & & 0.81 & 0.81 \\
E shelf, summer & 0.19 & 0.19 & & 0.43 & 0.23 \\
W offshore, summer & 0.14 & 0.14 & & 0.36 & 0.35 & 0.28 \\
E offshore, summer & 0.17 & 0.12 & & 0.40 & 0.31 \\
\hline
\end{tabular}



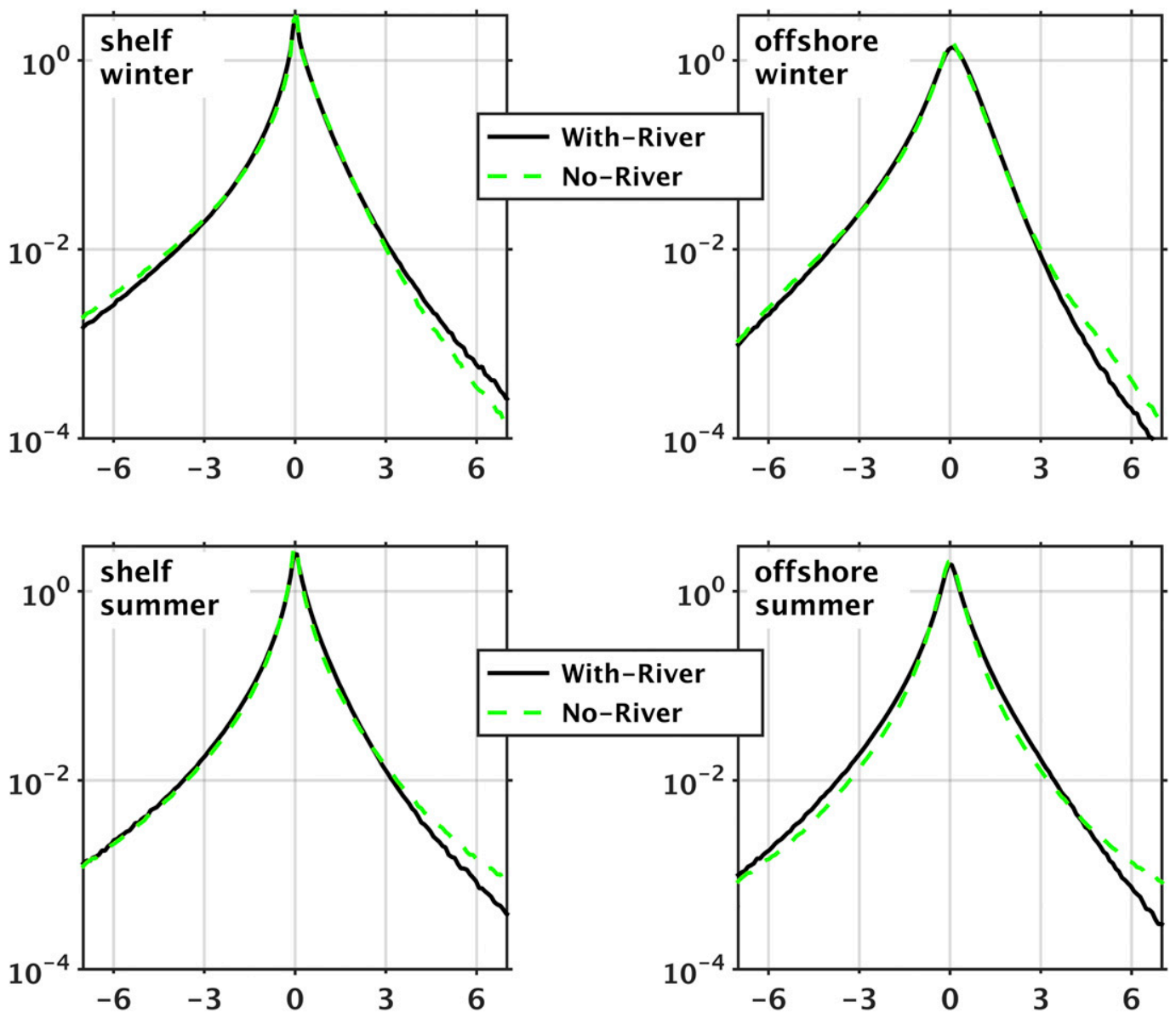

FIG. 17. PDFs of surface $\delta / f$ normalized by $\operatorname{RMS}(\delta / f)$ on the shelf and offshore regions (see Fig. 16) during winter and summer months: $500-\mathrm{m}$ solutions.

turbulence in the vicinity of a horizontal buoyancy gradient (Gula et al. 2014; McWilliams et al. 2015).

Careful testing of the different scaling arguments in (2) for various flow features in the solutions would require additional model realizations under different river forcing and wind forcing scenarios and is beyond the scope of this paper. Nevertheless, all of the scaling arguments in (2) show a strong dependency of the secondary circulation and APE to EKE buoyancy conversion on the surface boundary layer depth $h_{\mathrm{BL}}$ and lateral buoyancy gradient magnitude $\left|\nabla_{h} b\right|$. As shown in Figs. 11 and 12, the rivers' outflow produces strong buoyancy gradients as well as shallow boundary layer depths, both of which have opposite effects on submesoscale circulations. The sensitivity of the scaling of $\phi_{\text {MLE }}$ and $\phi_{\text {TTW }}$ to seasonal changes and river forcing is illustrated in Figs. 19 and 20. Our integration time is too short to assess whether differences in $\phi_{\text {STRAIN }}$, which depends on mesoscale straining motions, are associated with river forcing or mesoscale variability, and the corresponding fields are not shown. During winter, $\phi_{\mathrm{MLE}}$ is considerably weaker in regions directly affected by the river outflow (Fig. 19a), whereas $\phi_{\text {TTW }}$ (Fig. 19b) exhibits similar magnitudes throughout the entire computational domain (excluding very shallow estuaries). This suggests that mixed layer eddies, which are more sensitive to variations in boundary layer depth $\left[h_{\mathrm{BL}}^{2}\right.$ dependence in (2a)] compared with boundary layer turbulence $\left[h_{\mathrm{BL}}\right.$ dependence in (2c)] may be locally suppressed by river forcing (Fig. 19a vs Fig. 19c). During summer, both $\phi_{\text {MLE }}$ and $\phi_{\text {TTW }}$ are reduced in the No-River solution (Fig. 20, top vs bottom panels), suggesting that the river-induced lateral buoyancy gradients are dynamically more important than the corresponding reduction in boundary layer depth. This may be a consequence of generally having shallower boundary layers in summer compared with winter, making the effect of the shallow $h_{\mathrm{BL}}$ river anomaly less significant than in winter.

The root-mean-square values of $\phi_{\mathrm{MLE}}$ and $\phi_{\mathrm{TTW}}$ in flow regions that are dynamically linked to the river outflow and have weak mesoscale variability are shown in Table 5. In summer, both $\operatorname{RMS}\left(\phi_{\mathrm{MLE}}\right)$ and RMS 

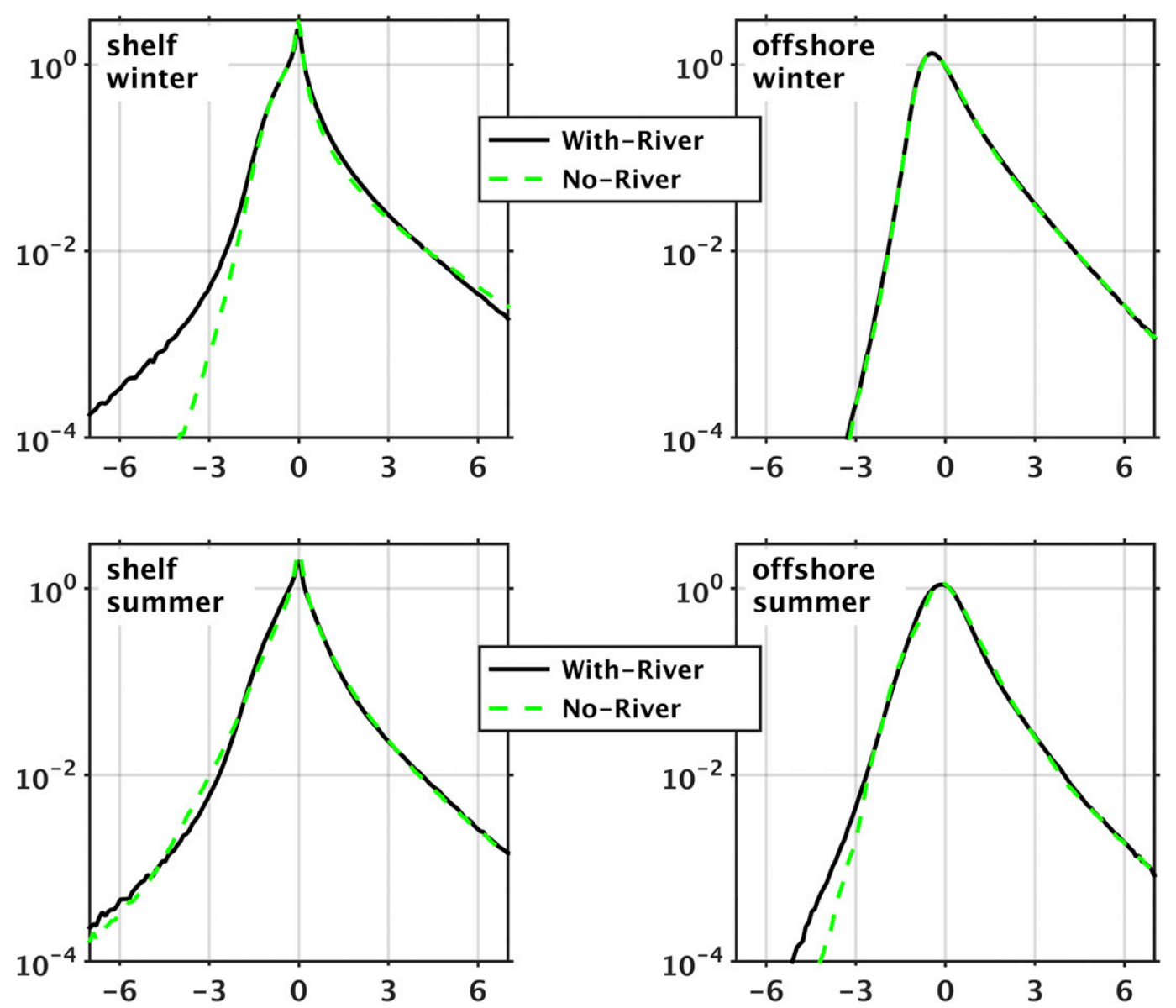

FIG. 18. PDFs of surface $\zeta / f$ normalized by RMS $(\zeta / f)$ on the shelf and offshore regions (see Fig. 16) during winter and summer months: 500-m solutions.

$\left(\phi_{\text {TTW }}\right)$ are reduced in the No-River solution, in agreement with Tables 3 and 4 . In winter, $\operatorname{RMS}\left(\phi_{\mathrm{MLE}}\right)$ is enhanced in the No-River solution in regions that are directly influenced by river forcing, as suggested by Figs. 19a and $19 \mathrm{c}$, whereas $\operatorname{RMS}\left(\phi_{\mathrm{TTW}}\right)$ is in fact reduced. Because $\phi_{\mathrm{MLE}}$ and $\phi_{\mathrm{TTW}}$ are merely scaling estimates, they cannot be directly compared with one another in a single model solution. Nevertheless, this result suggests that river forcing may locally suppress mixed layer eddy generation during winter. Since winter months are generally submesoscale active, a number of other generating processes may be at play, and the overall effect of river forcing on submesoscale metrics is more subtle. On the contrary, during summer, when the boundary layer is shallower and submesoscale currents are less energetic, the differences between With-River

TABLE 4. Root-mean-square normalized divergence RMS $(\delta / f)$ and vorticity RMS $(\zeta / f)$ for the 500-m With-River and No-River solutions in regions with SSH anomaly magnitudes smaller than $0.2 \mathrm{~m}$ (i.e., outside of strong mesoscale currents). Fresh/salty denote flow regions with salinity values lower/larger than 36.25 psu during winter and 35.5 psu during summer, based on the With-River solution. Maximal RMS standard errors are 0.03 for $\operatorname{RMS}(\delta / f)$ and 0.05 for $\operatorname{RMS}(\zeta / f)$, where the number of degrees of freedom is based on an assumed decorrelation time scale of 3 days and an assumed decorrelation length scale of $10 \mathrm{~km}$.

\begin{tabular}{lcccc}
\hline \hline & \multicolumn{2}{c}{$\operatorname{RMS}(\delta / f)$} & \multicolumn{2}{c}{ RMS $(\zeta / f)$} \\
\cline { 2 - 3 } \multicolumn{1}{c}{ Threshold criterion, season } & With-River & No-River & With-River \\
\hline Fresh, submesoscales, winter & 0.47 & 0.54 & 0.70 \\
Salty, submesoscales, winter & 0.44 & 0.52 & 0.75 & 0.72 \\
Fresh, submesoscales, summer & 0.21 & 0.15 & 0.43 & 0.78 \\
Salty, submesoscales, summer & 0.17 & 0.15 & 0.40 \\
\hline
\end{tabular}



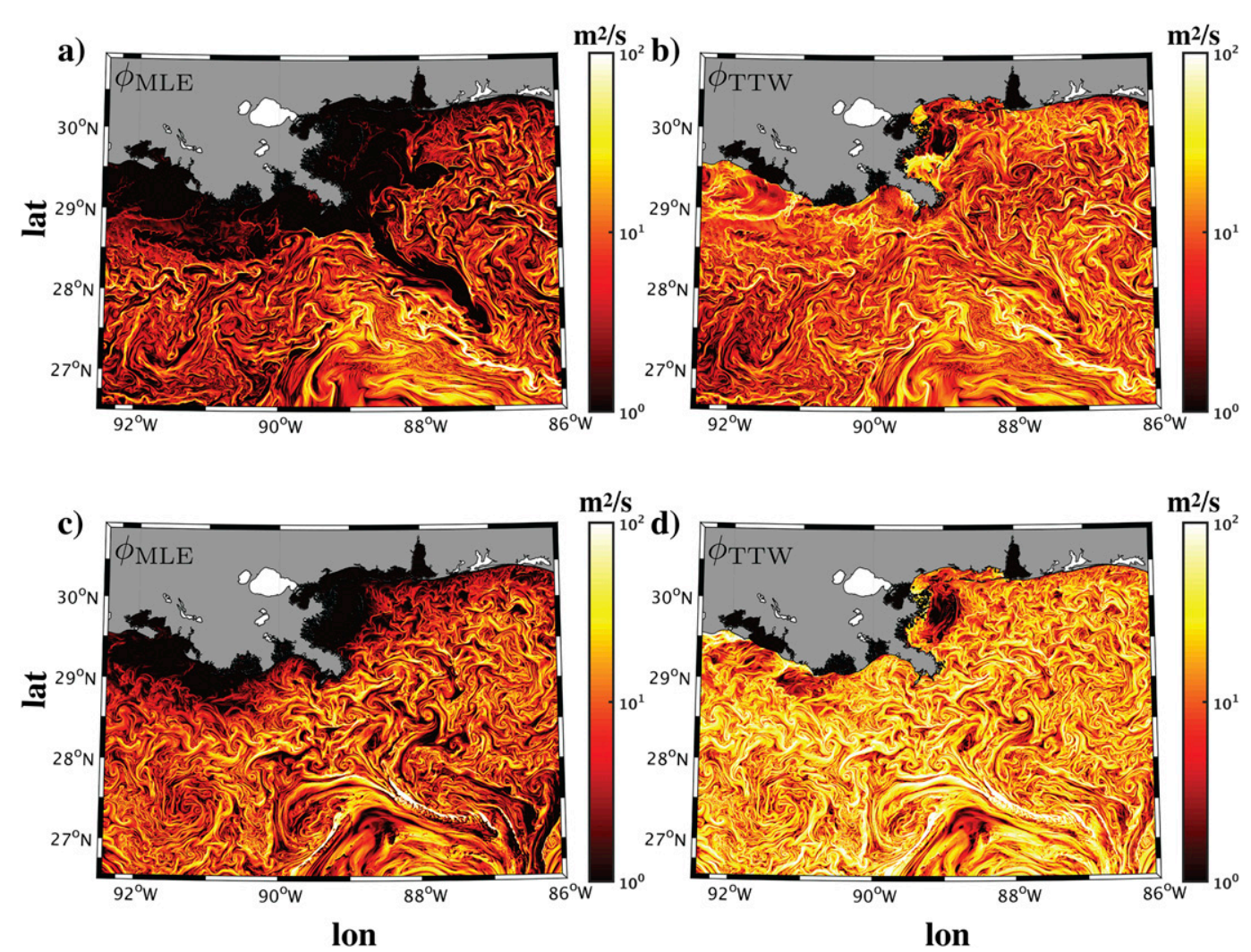

FIG. 19. Representative surface snapshot during winter of $\phi_{\text {MILE }}$ and $\phi_{\mathrm{TTW}}[(2)]$ for (a),(b) the 500-m With-River and (c),(d) 500-m No-River solutions.

and No-River solutions are more pronounced, suggesting that river forcing dominates submesoscale generation.

\section{Summary and conclusions}

Realistic, submesoscale-resolving numerical simulations are used to investigate submesoscale dynamics in the northern Gulf of Mexico (GoM), the location where the 2010 Deepwater Horizon oil spill took place as well as the GLAD, LASER, and SPLASH field experiments. In the current manuscript, the first of three companion papers, the focus is on what effect the MississippiAtchafalaya River system has on the generation of submesoscale currents during winter and summer, on and off the shelf, and east and west of the Mississippi River delta.

Analysis of vorticity, horizontal divergence, and APE to EKE energy conversion demonstrates that river outflow has a quantifiable effect on submesoscale currents in the northern GoM region. During winter, No-River solutions have, on average, larger horizontal divergence, and more APE to EKE conversion than With-River solutions, implying that the rivers suppress submesoscale generation. On the contrary, during summer, No-River solutions have, on average, smaller horizontal divergence and vorticity variances and less APE to EKE conversion than With-River solutions, implying that the rivers enhance submesoscale generation. These results confirm the findings of L16, using numerical solutions with 3 to 10 times higher horizontal resolution. In addition, because of our superior river implementation, we are able to extend their results and spatially characterize the rivers' impact on submesoscale circulation in the region.

Specifically, we show that the suppression of submesoscale currents during winter is most prominent to the east of the Bird's Foot and offshore, where the signature of the Mississippi River jet is strongest. Analysis of scaling laws for the generation of submesoscale currents suggests that the decrease in boundary layer depth in flow regions occupied by the river outflow reduces the generation of mixed layer eddies and, consequently, the seasonally averaged submesoscale variability.

During summer, the enhancement of submesoscale currents is significant both east and west of the Bird's Foot, on and off the shelf, and is most prominent in the vorticity field. The scaling law analysis suggests that the rivers enhance lateral buoyancy gradients throughout most of the region and consequently the generation of 

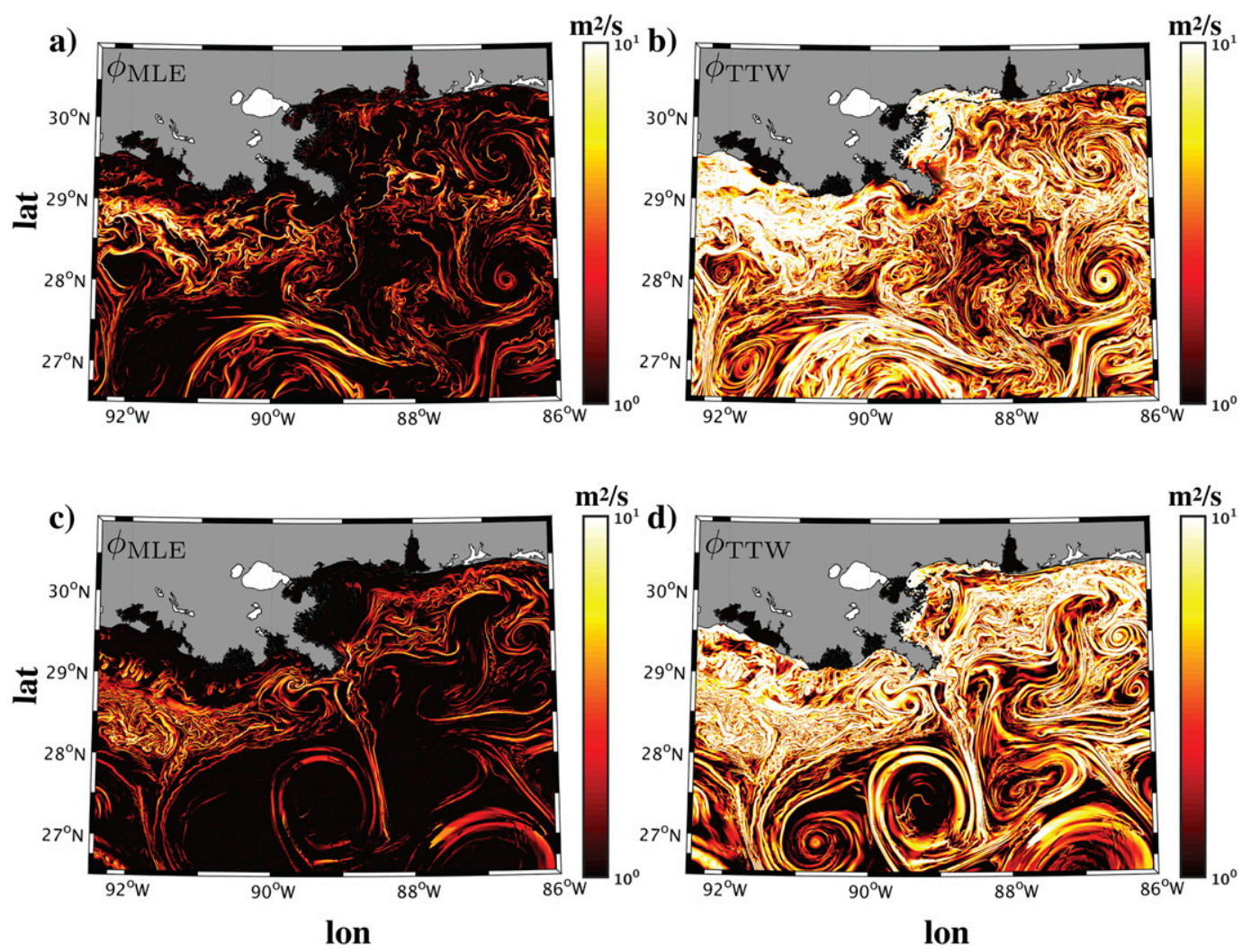

FIG. 20. As in Fig. 19, but during summer. Note the different color bar range compared with Fig. 19.

submesoscale currents due to both turbulent boundary layer processes and mixed layer eddies. Because in summer the mixed layer is shallowest, the generation of submesoscale currents in the absence of riverine forcing is weak and the differences between WithRiver and No-River solutions are substantial. During winter, however, the mixed layer is deepest in both cases, and therefore a variety of processes can lead to the generation of submesoscale currents, even in the absence of riverine forcing. As a result, the differences between With-River and No-River solutions are more subtle.
Geographically, for both With-River and No-River solutions, stronger submesoscale currents are found offshore during winter but closer to the shelf during summer. In winter, for both With-River and No-River solutions, the submesoscale current magnitudes offshore are stronger east of the Bird's Foot. In summer, the magnitudes in the With-River solution are still larger east of the Bird's Foot offshore, but closer to the shelf they are larger to the west.

It is important to note that the differences caused by the presence and absence of river forcing are weaker than the seasonal variability and, in some of the cases, the shelf-offshore variability. This could be due to lack

TABLE 5. Root-mean-square $\phi_{\text {MILE }}$ and $\phi_{\text {TTW }}$ [Eqs. (2)] for 500-m With-River and No-River solutions in regions with SSH anomaly magnitudes smaller than $0.2 \mathrm{~m}$ (i.e., outside of strong mesoscale currents). Fresh/salty denote flow regions with salinity values lower/larger than 36.25 psu during winter and 35.5 psu during summer, based on the With-River solution. Maximal RMS standard errors are $7.5 \%$ of the signal, where the number of degrees of freedom is based on an assumed decorrelation time scale of 3 days and an assumed decorrelation length scale of $10 \mathrm{~km}$.

\begin{tabular}{lcccr}
\hline \hline & \multicolumn{2}{c}{ RMS $\left(\phi_{\text {MILE }}\right)$} & \multicolumn{2}{c}{ RMS $\left(\phi_{\text {TTW }}\right)$} \\
\cline { 2 - 3 } Threshold criterion, season & With-River & No-River & With-River & No-River \\
\hline Fresh, submesoscales, winter & 5.9 & 8.2 & 31.5 & 25.9 \\
Salty, submesoscales, winter & 14.7 & 13.4 & 30.1 & 28.5 \\
Fresh, submesoscales, summer & 1.3 & 0.9 & 12.0 & 4.6 \\
Salty, submesoscales, summer & 1.5 & 1.0 & 7.7 \\
\hline
\end{tabular}



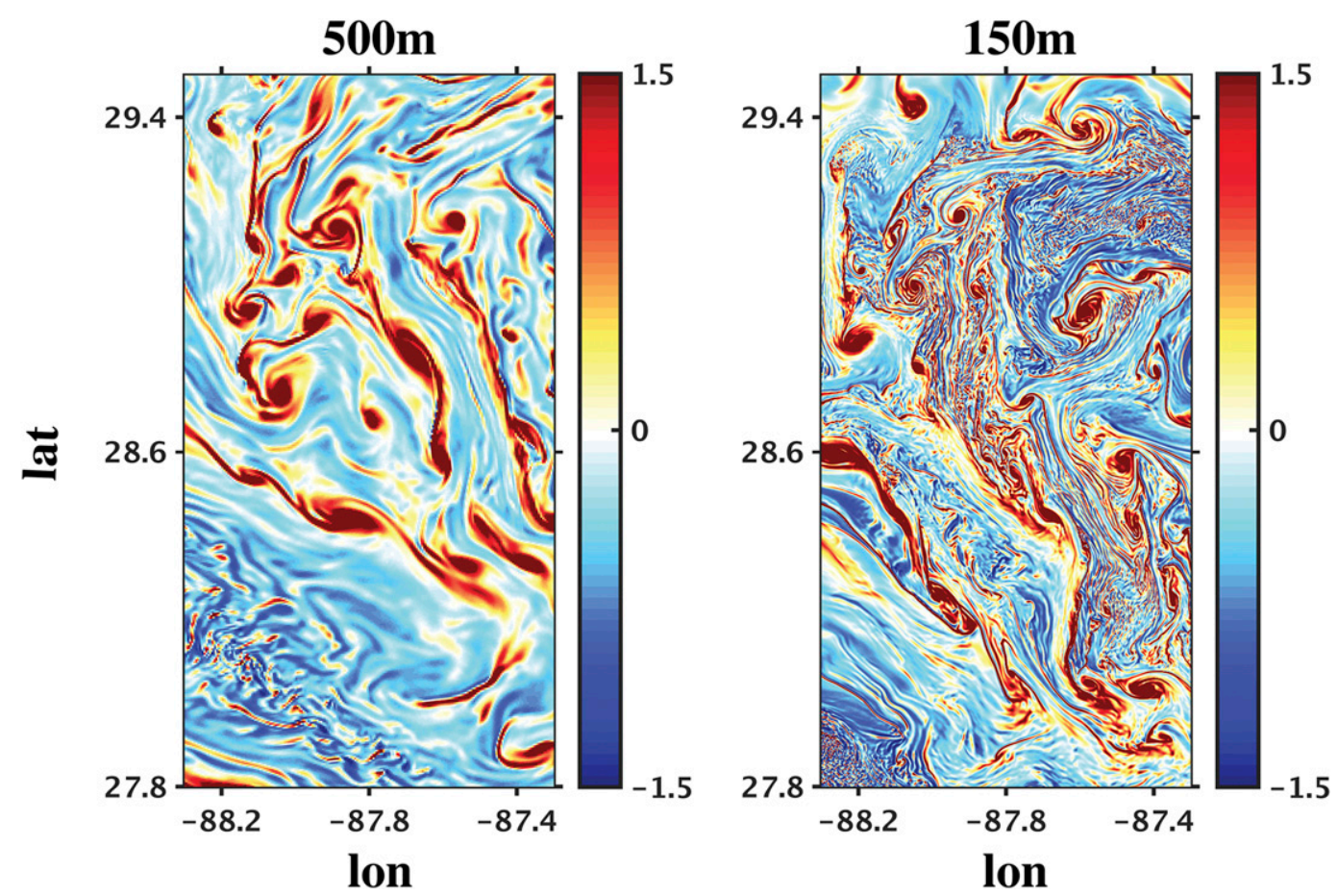

FIG. 21. Surface Rossby number $\zeta / f$ snapshots at the same instant in time from the 500 - and 150 -m solutions.

of resolution on the shelf and the numerical river implementation used (section 2) that may lead to an underrepresentation of the offshore freshwater transport.

Our modeling approach lacks a number of physical processes that could affect our results. First, the current river implementation (section 2) does not account for the momentum flux associated with real river outflow. In addition, it does not represent the entire vertical extent associated with realistic river forcing and confines its influence to an overly thin near-surface layer. Furthermore, the large interannual variability of the MississippiAtchafalaya River system outflow, the mesoscale circulations, and the wind forcing could affect the spatiotemporal distribution of river water in this region and therefore of the associated submesoscale currents. Tidal effects, highfrequency wind forcing, and averaged surface wave effects are also neglected. In future work, where we aim to focus on near-shelf processes, we plan to improve river forcing implementation and gradually include tidal, surface wave, and high-frequency wind effects.

In section 4, we demonstrate that the submesoscale measures used in our analysis have yet to converge across the different resolution nests. In addition, the approximate mixed layer Rossby deformation radius in (1) illustrates that the horizontal resolution required to resolve submesoscale currents may be higher closer to the shelf and in summer, where and when the mixed layer depth is shallower. Figure 21 shows surface Rossby number snapshots from the 500- and 150-m solutions. Clearly, the 500-m solution fails to represent some of the finescale structures found in the 150-m snapshot in the interior of the cyclonic eddies and at the edges of the fronts and filaments. Nevertheless, there are some similarities between the two solutions, particularly with respect to the general shape and size of the cyclonic vortices, fronts, and filaments. The qualitative difference and similarities in these solutions illustrate the need to identify quantifiable, resolutionindependent, submesoscale measures to adequately express which aspects of the submesoscale features are well represented by a numerical solution and which require additional resolution refinement.

Acknowledgments. This work was made possible by a grant from the Gulf of Mexico Research Initiative through the CARTHE Consortium. Data are publicly available through the Gulf of Mexico Research Initiative Information and Data Cooperative (GRIIDC) online (at https://data.gulfresearchinitiative.org; https:// doi.org/10.7266/N7PK0DK2, https://doi.org/10.7266/ N7F18X4S, https://doi.org/10.7266/N75H7DQ5, https:// doi.org/10.7266/N7JS9NVS, and https://doi.org/10.7266/ N79885FW). RB, JCM, and AFS are further supported by ONR N000141410626. LR is also supported by NSF Grant OCE-1419450. The Extreme Science and Engineering Discovery Environment (XSEDE) provide support for computing. 


\section{REFERENCES}

Andersson, A., K. Fennig, C. Klepp, S. Bakan, H. Graßl, and J. Schulz, 2010: The Hamburg Ocean Atmosphere Parameters and Fluxes from Satellite Data-HOAPS-3. Earth Syst. Sci. Data, 2, 215-234, doi:10.5194/essd-2-215-2010.

Antonov, J. I., and Coauthors, 2009: Salinity. Vol. 2, World Ocean Atlas 2009, NOAA Atlas NESDIS 69, 184 pp.

Barkan, R., J. C. McWilliams, M. J. Molemaker, J. Choi, K. Srinivasan, A. F. Shchepetkin, and A. Bracco, 2017: Submesoscale dynamics in the northern Gulf of Mexico. Part II: Temperature-salinity compensation and cross-shelf transport processes. J. Phys. Oceanogr., 47, 2347-2360, https://doi.org/10.1175/JPO-D-17-0040.1.

Boccaletti, G., R. Ferrari, and B. Fox-Kemper, 2007: Mixed layer instabilities and restratification. J. Phys. Oceanogr., 37, 2228-2250, doi:10.1175/JPO3101.1.

Callies, J., R. Ferrari, J. M. Klymak, and J. Gula, 2015: Seasonality in submesoscale turbulence. Nat. Commun., 6, 6862, https:// doi.org/10.1038/ncomms7862.

Capet, X., J. C. McWilliams, M. J. Molemaker, and A. F. Shchepetkin, 2008: Mesoscale to submesoscale transition in the California Current System. Part I: Flow structure, eddy flux, and observational tests. J. Phys. Oceanogr., 38, 29-43, doi:10.1175/2007JPO3671.1.

Carton, J. A., and B. S. Giese, 2008: A reanalysis of ocean climate using Simple Ocean Data Assimilation (SODA). Mon. Wea. Rev., 136, 2999-3017, doi:10.1175/2007MWR1978.1.

Choi, J., A. Bracco, R. Barkan, A. F. Shchepetkin, J. C. McWilliams, and M. J. Molemaker, 2017: Submesoscale dynamics in the northern Gulf of Mexico. Part III: Lagrangian implications. J. Phys. Oceanogr., 47, 2361-2376, https://doi.org/ 10.1175/JPO-D-17-0036.1.

Crone, T. J., and M. Tolstoy, 2010: Magnitude of the 2010 Gulf of Mexico oil leak. Science, 330, 634-634, doi:10.1126/science.1195840.

Dai, A., and K. E. Trenberth, 2002: Estimates of freshwater discharge from continents: Latitudinal and seasonal variations. J. Hydrometeor., 3, 660-687, doi:10.1175/ 1525-7541(2002)003<0660:EOFDFC > 2.0.CO; 2.

de Boyer Montégut, C., G. Madec, A. S. Fischer, A. Lazar, and D. Iudicone, 2004: Mixed layer depth over the global ocean: An examination of profile data and a profile-based climatology. J. Geophys. Res., 109, C12003, doi:10.1029/2004JC002378.

Fox-Kemper, B., R. Ferrari, and R. Hallberg, 2008: Parameterization of mixed layer eddies. Part I: Theory and diagnosis. J. Phys. Oceanogr., 38, 1145-1165, doi:10.1175/2007JPO3792.1.

Gula, J., M. J. Molemaker, and J. C. McWilliams, 2014: Submesoscale cold filaments in the Gulf Stream. J. Phys. Oceanogr., 44, 2617-2643, doi:10.1175/JPO-D-14-0029.1.

LaCasce, J., 2008: Statistics from Lagrangian observations. Prog. Oceanogr., 77, 1-29, doi:10.1016/j.pocean.2008.02.002.

Large, W. G., and S. Yeager, 2009: The global climatology of an interannually varying air-sea flux data set. Climate Dyn., 33, 341-364, doi:10.1007/s00382-008-0441-3.

_ J. C. McWilliams, and S. C. Doney, 1994: Oceanic vertical mixing: A review and a model with a nonlocal boundary layer parameterization. Rev. Geophys., 32, 363-403, doi:10.1029/94RG01872.

Lemarié, F., J. Kurian, A. F. Shchepetkin, M. J. Molemaker, F. Colas, and J. C. McWilliams, 2012: Are there inescapable issues prohibiting the use of terrain-following coordinates in climate models? Ocean Modell., 42, 57-79, doi:10.1016/j.ocemod.2011.11.007.

Locarnini, R. A., and Coauthors, 2013: Temperature. Vol. 1, World Ocean Atlas 2013, NOAA Atlas NESDIS 73, 40 pp.

Luo, H., A. Bracco, Y. Cardona, and J. C. McWilliams, 2016: Submesoscale circulation in the northern Gulf of Mexico: Surface processes and the impact of the freshwater river input. Ocean Modell., 101, 68-82, doi:10.1016/j.ocemod.2016.03.003.

Mason, E., J. Molemaker, A. F. Shchepetkin, F. Colas, J. C. McWilliams, and P. Sangrà, 2010: Procedures for offline grid nesting in regional ocean models. Ocean Modell., 35, 1-15, doi:10.1016/j.ocemod.2010.05.007.

McWilliams, J. C., 2016: Submesoscale currents in the ocean. Proc. Roy. Soc. London, A472, 20160117, https://doi.org/10.1098/rspa.2016.0117.

_ _ J. Gula, M. J. Molemaker, L. Renault, and A. F. Shchepetkin, 2015: Filament frontogenesis by boundary layer turbulence. J. Phys. Oceanogr., 45, 1988-2005, doi:10.1175/JPO-D-14-0211.1.

Mensa, J. A., Z. Garraffo, A. Griffa, T. M. Özgökmen, A. Haza, and M. Veneziani, 2013: Seasonality of the submesoscale dynamics in the Gulf Stream region. Ocean Dyn., 63, 923-941, doi:10.1007/s10236-013-0633-1.

Müller-Karger, F. E., J. J. Walsh, R. H. Evans, and M. B. Meyers, 1991: On the seasonal phytoplankton concentration and sea surface temperature cycles of the Gulf of Mexico as determined by satellites. J. Geophys. Res., 96, 12 645-12 665, doi:10.1029/91JC00787.

_ graphic conditions in the offshore Gulf of Mexico. Prog. Oceanogr., 134, 54-76, doi:10.1016/j.pocean.2014.12.007.

Poje, A. C., and Coauthors, 2014: Submesoscale dispersion in the vicinity of the Deepwater Horizon spill. Proc. Natl. Acad. Sci. USA, 111, 12 693-12 698, doi:10.1073/pnas.1402452111.

Renault, L., M. J. Molemaker, J. Gula, S. Masson, and J. C. McWilliams, 2016a: Control and stabilization of the Gulf Stream by oceanic current interaction with the atmosphere. J. Phys. Oceanogr., 46, 3439-3453, doi:10.1175/JPO-D-16-0115.1.

- - - J. C. McWilliams, A. F. Shchepetkin, F. Lemarié, D. Chelton, S. Illig, and A. Hall, 2016b: Modulation of wind work by oceanic current interaction with the atmosphere. J. Phys. Oceanogr., 46, 1685-1704, doi:10.1175/JPO-D-15-0232.1.

Risien, C. M., and D. B. Chelton, 2008: A global climatology of surface wind and wind stress fields from eight years of QuikSCAT scatterometer data. J. Phys. Oceanogr., 38, 2379-2413, doi:10.1175/2008JPO3881.1.

Shchepetkin, A. F., 2015: An adaptive, Courant-number-dependent implicit scheme for vertical advection in oceanic modeling. Ocean Modell., 91, 38-69, doi:10.1016/j.ocemod.2015.03.006.

_ , and J. C. McWilliams, 2005: The Regional Oceanic Modeling System: A split-explicit, free-surface, topography-followingcoordinate oceanic model. Ocean Modell., 9, 347-404, doi:10.1016/j.ocemod.2004.08.002.

— forecasting in terrain-following coordinates: Formulation and skill assessment of the regional ocean modeling system" by Haidvogel et al., J. Comp. Phys. 227, pp. 3595-3624. J. Comput. Phys., 228, 8985-9000, doi:10.1016/j.jcp.2009.09.002.

— and - 2011: Accurate Boussinesq oceanic modeling with a practical, stiffened equation of state. Ocean Modell., 38, 41-70, doi:10.1016/j.ocemod.2011.01.010.

Shcherbina, A. Y., E. A. D'Asaro, C. M. Lee, J. M. Klymak, M. J. Molemaker, and J. C. McWilliams, 2013: Statistics of vertical vorticity, divergence, and strain in a developed submesoscale turbulence field. Geophys. Res. Lett., 40, 4706-4711, doi:10.1002/grl.50919.

Sheinbaum, J., J. Candela, A. Badan, and J. Ochoa, 2002: Flow structure and transport in the Yucatan Channel. Geophys. Res. Lett., 29, 1040, https://doi.org/10.1029/2001GL013990.

Thomas, L. N., A. Tandon, and A. Mahadevan, 2008: Submesoscale processes and dynamics. Ocean Modeling in an Eddying Regime, Geophys. Monogr., Vol. 177, Amer. Geophys. Union, 17-38. 